
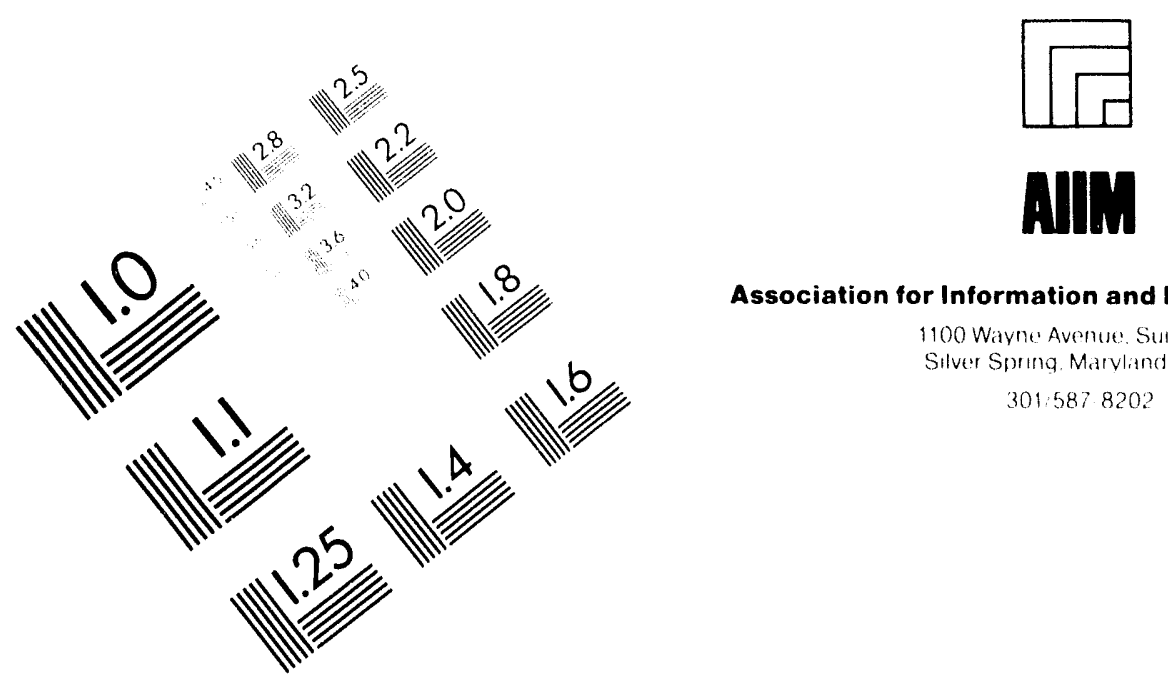

Association for Information and Image Management 1100 Wavne Avenue Sute 1100 Siver Sprng. Maryland 20910 301587820 ?

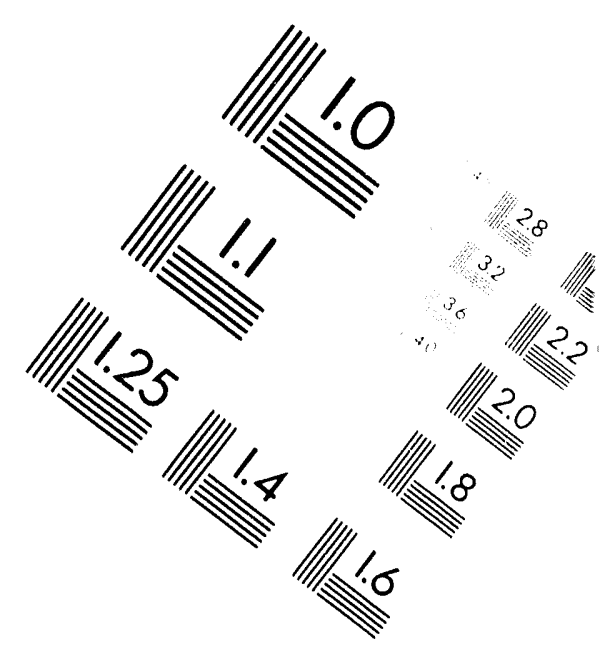

Centimeter

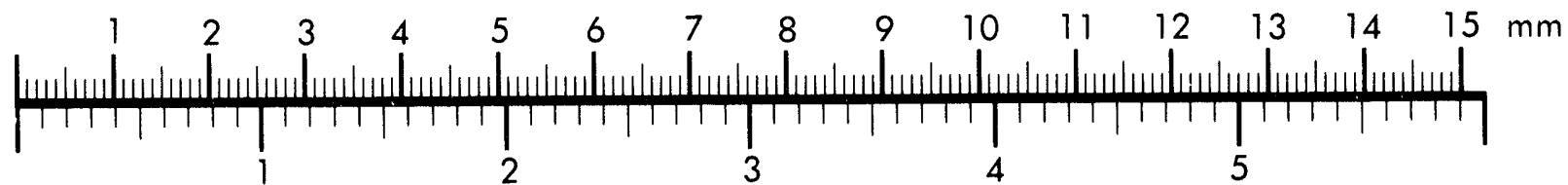
Inches
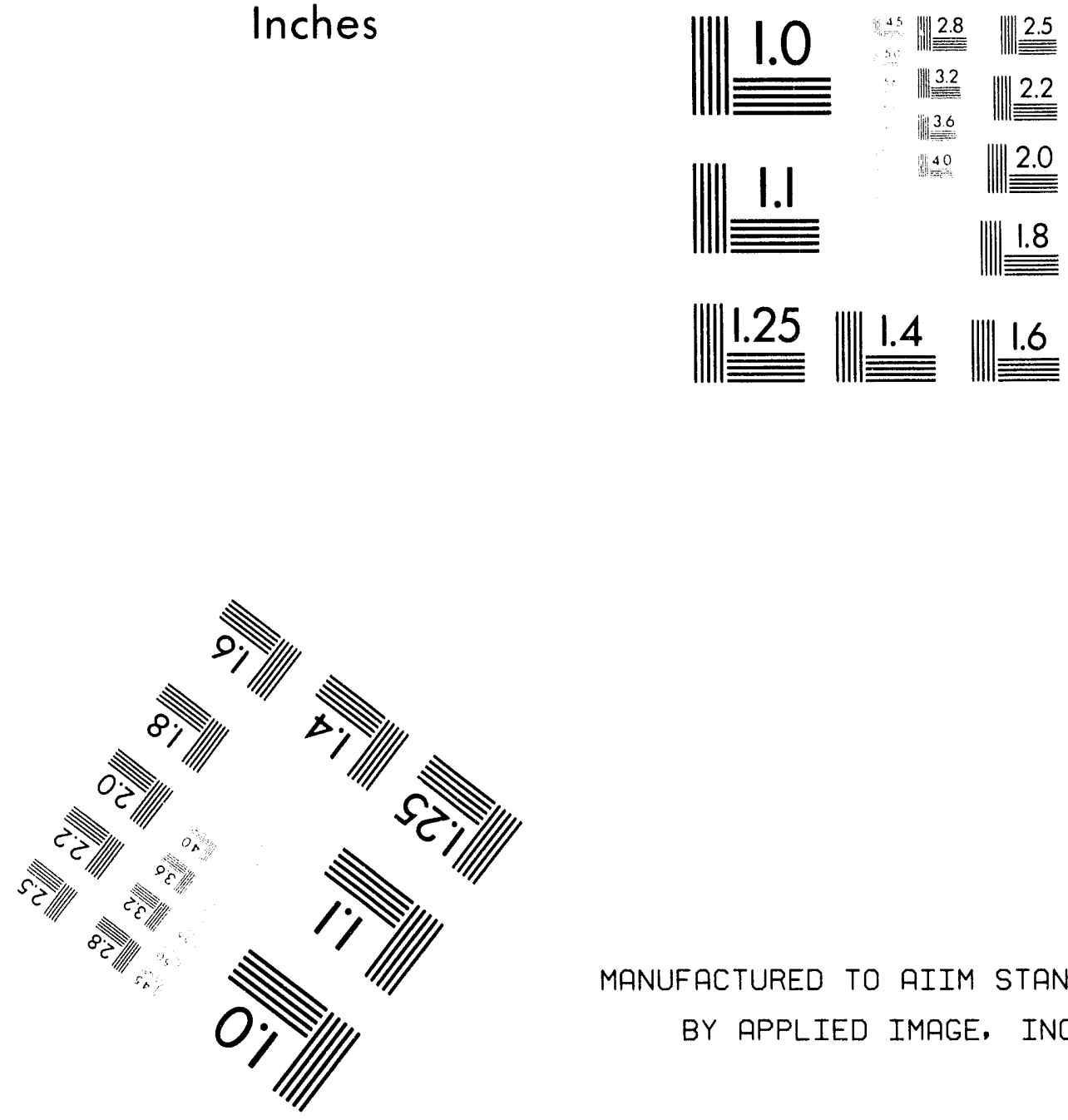

MANUFACTURED TO AIIM STANDARDS

BY APPLIED IMAGE, INC.

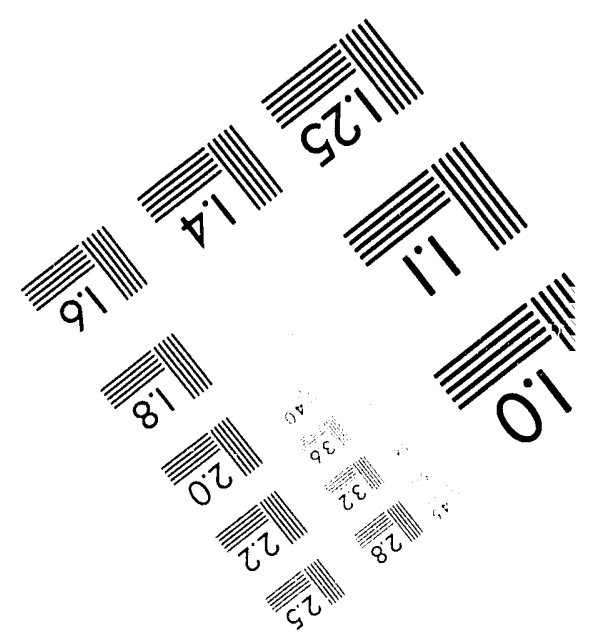



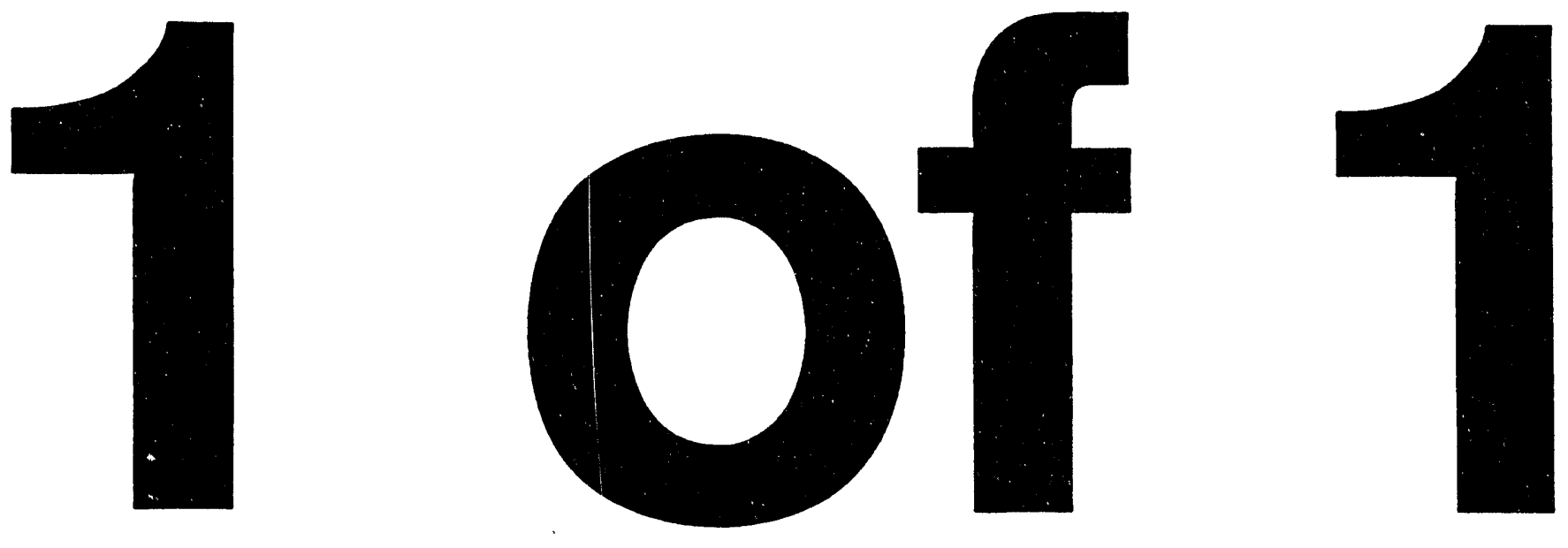


\title{
Study of the Effect of the Space Charge using SYNCH
}

\author{
A.F. Haffmans, D. Maletić, and A.G. Ruggiero
}

April 25, 1994

Department of Advanced Technology

Informal Report

Brookhaven National Laboratory

Associated Universities, Inc.

Upton, Long Island, New York 11973 


\section{Abstract *}

The interparticle repulsion, or space charge, limits the density of charged-particle beams that can be obtained in storage rings. In this report we study the effect of increasing the space charge, with an exact computation of the lattice parameters using SYNCH. Systematically increasing the ion density by decreasing the emittance with cooling techniques lowers the betatron tune, until the lower half-integral stopband resonance - also induced by the beam is reached. In the simple model described in the report, the amount of "cooling" is limited by the encountered stopband of the lattice. Therefore, machines with a higher tune and larger periodicity are better suited to store beams with high space charge.

\footnotetext{
*Work perfomed under the auspices of the U.S Department of Energy.
} 


\section{Introduction}

In conventional storage rings the interparticle repulsion limits the density of the ions in the beam. Moreover, coling techniques that have been proposed to increase the ion beam density, for instance to generate crystalline structures, simultaneously introduce the interparticle - or mean field - potential as a significant effect in the equations of motion [1].

For small or moderate ion densities, the effect of the spacecharge force can be found perturbatively. However, one objective is to cool the beam extensively, to be able to observe the different crystalline structures of such a beam, which have been speculated to appear at very large tune depressions.

For extremely high ion density, the space-charge force can no longer be considered a small perturbation, and one needs to model the effect of increasing the space-charge force carefully to determine to what extent the perturbative approach is still valid. We report such a study below. We consistently model the space charge to determine the change in storage ring parameters using a code like SYNCH [2].

\section{Modeling the Space Charge}

The equations of motion in the storage ring have the form $[3]^{\dagger}$ :

$$
y^{\prime \prime}+K_{v}(s) y=K_{s c}(s) y
$$

with an analogous equation for $x . K_{h, v}$ are the lattice focussing functions, which are periodic functions along the lattice of the stor-

\footnotetext{
${ }^{\dagger}$ In the following we will focus on the equations of motion in the vertical - or $y$ - direction, but the equations of motion in the $x$-direction - and their method of solution - are identical. Moreover, the path length $s$ is taken as the independent variable.
} 
age ring. $K_{s c}$ is the effect of the space charge, and in general also a function of $s$. For a dilute beam, i.e. $K_{s c}=0$, the solution to Eq. (1) is well known, and can be found for instance using SYNCH, and described in terms of the amplitude lattice functions $\beta_{h, v}$ and betatron tunes $\nu_{h, v} . K_{s c}$ is of the form:

$$
K_{s c}=\frac{K}{\beta_{v}},
$$

where $K$ is a constant. Eq. (2) is derived in the Appendix for the case of a uniform beam with elliptical cross section. In fact we find for a "round" beam with the same betatron emittance $\epsilon$ in the radial and vertical direction:

$$
K=\frac{2 \pi N r_{0} f_{0} Q^{2}}{A \beta^{2} \gamma^{3} \alpha(\eta) \epsilon}
$$

$\alpha(\eta)$ is a function of the aspect ratio $\eta=\sqrt{\beta_{h} / \beta_{v}}$, and is plotted in Fig. 1. To solve Eq. (1) for nondilute beams, we need to know the cross section at each point of the beam, which in its turn depends on the space charge. Thus, we start with an initial guess for the cross section (e.g., for a dilute beam), and iterate until we find a self-consistent solution.

To take the space charge into account, we model the interaction within a magnet element of the storage ring as a sequence of kicks at fixed positions $s_{k}$ along the beam's trajectory. In the proximity of the kick the equation of motion reduces to:

$$
\begin{aligned}
y^{\prime \prime} & =\frac{K_{0}}{\beta_{v}} \delta\left(s-s_{k}\right) \\
K_{0} & =K^{\prime} \times L_{k} .
\end{aligned}
$$

$L_{k}$ is the interaction length replaced by the $\delta$ kick. The transfer matrix is easily obtained as:

$$
\Delta\left(s_{k}\right)=\left(\begin{array}{cc}
1 & 0 \\
\frac{K_{0}}{\beta_{v}} & 1
\end{array}\right)
$$


Study of the effect of space charge using SYNCH

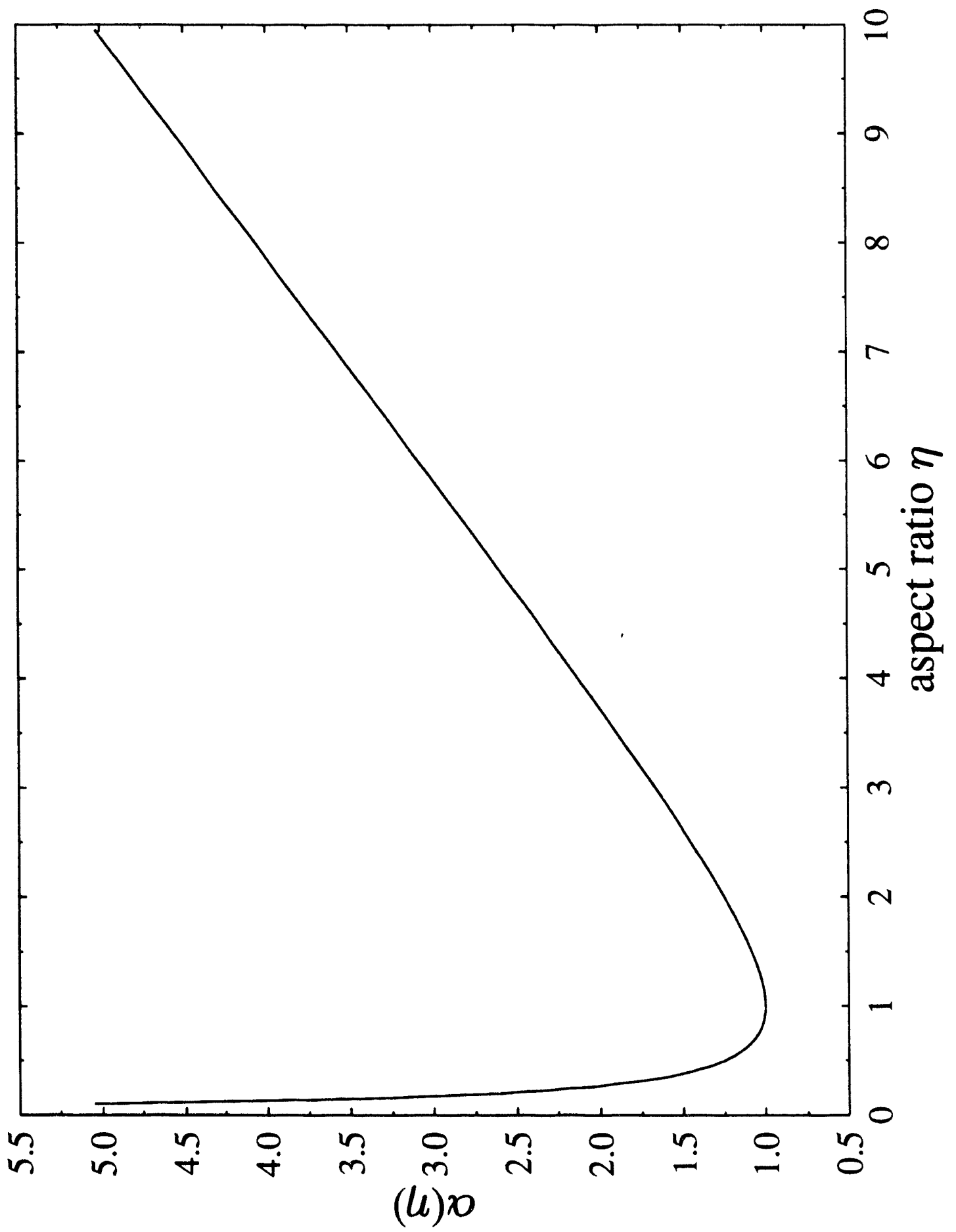

Figure 1: the function $\alpha(\eta)$. 
Between kicks the equations of motion are those of the dilute beam. Consequently, the transfer matrix for one revolution is of the form:

$$
M_{\text {total }}=\ldots M_{k} \Delta\left(s_{k}\right) M_{k+1} \Delta\left(s_{k+1}\right) \ldots
$$

\section{Solving the Equations of Motion}

Let us again state that we need to obtain a self-consistent solution to the set of equations:

$$
\begin{aligned}
y^{\prime \prime}+K_{v} y & =0 \\
y^{\prime \prime}-\frac{K_{0}}{\beta_{v}} \delta\left(s-s_{k}\right) & =0 \quad \text { between kicks, }
\end{aligned}
$$

To obtain a solution we use SYNCH, which allows us to insert transfer matrices in between the transfer matrices of the dilute beam, thereby allowing us to solve Eq. (8). In other words, SYNCH determines the transfer matrix in between kicks, and we tell SYNCH explicitly to multiply it with a transfer matrix of the form Eq. (6), so that we obtain the total transfer matrix Eq. (7).

As mentioned before, on account of the $\beta_{v}$ dependence of the kick amplitude, which in its turn follows only after the complete solution for one revolution is known, we use an iterative scheme to obtain a self-consistent solution. Specifically, we have written the program GETBETAS which extracts the $\beta$ values at each postion where a kick takes place from the SYNCH output file. It then calls SYNCH, using a new input file containing revised values for the kick amplitude $K_{0} / \beta_{v}$ for each transfer matrix $\Delta\left(s_{k}\right)$ (see Eq. (6)). If we symbollically denote one such operation by $T$, and the set of $\beta$ 's generated by SYNCH by the vector $\mathbf{x}$, we iterate T until:

$$
T \mathbf{x}_{i}-\mathbf{x}_{i} \leq \text { tolerance, }
$$

where the tolerance is of the order of $10^{-5} \mathrm{~m}$. 


\section{Test Lattices}

We have studied the effect of the space charge in this fashion for five different storage-ring lattices. Their characteristics are listed in Tables 2 to 8 . We have used a SYNCH - like notation to describe the lattice as a function of basic beamline elements. For example, - $4 \mathrm{CE}$ means that a fundamental period is made up of CE and its reflection (indicated by the negative sign), and the lattice has superperiod 4. CE may consist of more fundamental elements, like drifts, quadupoles or dipoles.

In the figures following the tables we display the lattice properties as a function of $K$. For the CRYSTAL8 lattice $L_{k}=10.00 \mathrm{~cm}$; for all other lattices $L_{k}=12.68 \mathrm{~cm}$.

In Table 1 we show the different lattices, the initial value (i.e. for $K_{s c}=0$ ) for the (global) horizontal tune $\nu_{h}$, and the final value for $\nu_{h}$ at the maximum value for $K$ for which a stable beam was obtained, together with the location $\bar{\nu}_{\text {stop }}$ of the stopbands (see our discussion below).

All lattices, with the exception of CRYSTAL8, consist of regular FODO cells. The simplest lattice (FODO16), which is our starting point, is made up of exactly 16 cells, which all include bending between the quadrupoles. This is the lattice with the highest periodicity. By adjusting the quadrupole gradient, we could also vary the phase advance per cell, and therefore the global betatron tune. The next lattice, FODO4, was obtained by inserting a straight section made up of two FODO cells, with the bending magnet removed, at four axially symmetric locations along the ring. The periodicity is reduced to four, and the circumference has increased correspondingly.

To study the effect of periodicity we then studied FODO8, which has periodicity eight. It has the same number of cells, and the same circumference as FODO4, but the empty FODO cell has been 
redistributed symmetrically in eight different locations.

Finally, the last lattice, FODO4R (which we judge to be more realistic from the operation point of view) has each long straight section of FODO4 replaced by a four-meter-long drift, with doublets of quadrupoles at each end. For this lattice all quadrupoles in the fundamental cell are tuned independently, whereas only two gradients (one for the focusing, and one for the defocusing quadrupole) were used in the previous FODO rings.

A feature common to all FODO lattices is that the betatron tunes in the horizontal and vertical plane are equal. This is not the case for the last lattice, CRYSTAL8, which has focusing doublets at either side of the bending magnet. The periodicity is eight, but the focusing is weaker, compared to the FODO family described above.

\section{Discussion}

The space-sharge force defocuses the beam, and the tunes will decrease as $K$ increases. In fact, the effect of the space charge is similar to an error in the field gradient, and can be treated as such [3]. Consequently, the tune decreases until it crosses into the stopband. If $P$ is the superperiod of the lattice, the stopbands are located at:

$$
\nu_{\text {stop }}=m \frac{P}{2} \quad m=0,1,2, \ldots
$$

The halfwidth of the stopband to first order is equal to the spacecharge-induced tune shift [3]. Therefore, the stopband located just below the initial value of the tune $\nu_{h}\left(\nu_{v}\right)$, limits the maximally obtainable value of the space-charge parameter $K$. Specifically, let $\bar{\nu}_{\text {stop }}$ be the stopband just below the initial tune $\nu_{h}^{i}\left(\nu_{v}^{i}\right)$. The final 
value of the tune at $K^{\max }$ is equal to:

$$
\nu_{h(v)}^{f}=\frac{\nu_{h(v)}^{i}+\bar{\nu}_{s t o p}}{2}
$$

The tune shift due to the space charge to first order is given by [3]:

$$
\Delta \nu=\frac{1}{4 \pi} \oint_{C} \beta(s) K_{s c} d s .
$$

We can use Eq. (12) to obtain a rough estimate of the maximum of the space-charge parameter $K$, given by Eq. (2). $K$ has a weak dependence on $s$ due to the function $\alpha$, and we set $\alpha=1$ everywhere, so that:

$$
\Delta \nu=\frac{K}{4 \pi} \oint_{C} d s=K \frac{R}{2}
$$

where $\mathrm{R}$ is the radius of the storage ring. Recalling the remarks made above we obtain the required estimate for the maximum of the space-charge parameter:

$$
K^{\max } \approx \frac{\nu_{h(v)}^{i}-\bar{\nu}_{s t o p}}{R}
$$

The estimate using Eq. (14) are also shown in Table 1. In Figs. 2 to 21 we show different ring characteristics as a function of the integrated space charge strength $K_{0}=L_{k} K$.

The results show that denser beams can be stored in lattices with higher periodicity and focusing. In addtion, we conclude that Eq. (12) gives the tune shift even for large values of the spacecharge force. 


\begin{tabular}{|c|c|c|c|c|c|}
\hline generic name & $\begin{array}{c}\text { initial } \\
\text { tune } \\
\nu_{h}\end{array}$ & $\begin{array}{l}\text { final } \\
\text { tune } \\
\nu_{h}\end{array}$ & $\begin{array}{c}\text { stopbands } \\
\bar{\nu}_{\text {stop }} \\
m=0,1, \ldots\end{array}$ & $\begin{array}{c}\max . \\
K\end{array}$ & $\begin{array}{c}\text { est. } \\
\max \\
k\end{array}$ \\
\hline \multirow[t]{4}{*}{ FODO16 } & 4.8 & 2.76 & \multirow[t]{4}{*}{$8 \times m$} & 0.87 & 0.74 \\
\hline & 4.0 & 2.29 & & 0.69 & 0.62 \\
\hline & 3.2 & 1.88 & & 0.55 & 0.50 \\
\hline & 2.4 & 1.44 & & 0.39 & 0.37 \\
\hline \multirow[t]{3}{*}{ FODO4 } & 5.8 & 4.76 & \multirow[t]{3}{*}{$2 \times m$} & 0.24 & 0.19 \\
\hline & 4.8 & 4.44 & & 0.08 & 0.08 \\
\hline & 3.6 & 2.90 & & 0.16 & 0.17 \\
\hline \multirow[t]{2}{*}{ FODO8 } & 7.2 & 5.37 & \multirow[t]{2}{*}{$4 \times m$} & 0.43 & 0.33 \\
\hline & 6.0 & 4.96 & & 0.24 & 0.21 \\
\hline FODO4R & 7.30 & 6.62 & $2 \times m$ & 0.16 & 0.13 \\
\hline \multirow{2}{*}{$\begin{array}{c}\text { CRYSTAL8 } \\
\nu_{v} \rightarrow\end{array}$} & 1.90 & 1.46 & \multirow[t]{2}{*}{$4 \times m$} & 0.10 & \multirow[t]{2}{*}{0.11} \\
\hline & 1.09 & 0.68 & & 0.10 & \\
\hline
\end{tabular}

Table 1: Overview of the initial and final tunes, as well as the maximum obtainable space-charge parameter $K$, as well as its estimate using Eq. (14) for the lattices discussed in this report. (Note that for the CRYSTAL8 ring $\nu_{h} \neq \nu_{v}$ ). 


\begin{tabular}{||c|c|c|c||}
\hline \multicolumn{4}{||c|}{ Magnetic rigidity $B \rho=6.59152 \mathrm{Tm} . \mid$} \\
\hline name & type & $\begin{array}{c}\text { length } \\
{[\mathrm{m}]}\end{array}$ & $\begin{array}{c}\mathrm{B} \\
{[\mathrm{T}]}\end{array}$ \\
\hline $\mathrm{S}$ & drift & 0.12688 & $\mathrm{~N} / \mathrm{A}$ \\
\hline $\mathrm{D}$ & quad & 0.12689 & $\mathrm{~N} / \mathrm{A}$ \\
\hline $\mathrm{F}$ & quad & 0.12689 & $\mathrm{~N} / \mathrm{A}$ \\
\hline $\mathrm{B}$ & dipole & 0.76132 & 1.7 \\
\hline Beamline : F S B S D \\
\hline Cycle $=-16$ Beamline \\
\hline Circumference : $40.60 \mathrm{~m}$ \\
\hline
\end{tabular}

Table 2: Parameters of the FODO16 ring.

\begin{tabular}{||c|c|c|c||}
\hline $\begin{array}{c}\text { tune } \\
\text { per cell }\end{array}$ & $\begin{array}{c}\text { Tune } \\
\text { Total }\end{array}$ & $\begin{array}{c}\text { Gradient } \\
\text { F }[\mathrm{Tm}]\end{array}$ & $\begin{array}{c}\text { Gradient } \\
\text { D [Tm] }\end{array}$ \\
\hline 0.30 & 4.8 & 34.43606 & -35.45682 \\
\hline 0.25 & 4.0 & 29.36353 & -30.09379 \\
\hline 0.20 & 3.2 & 24.20837 & -25.38010 \\
\hline 0.15 & 2.4 & 17.85840 & -19.09617 \\
\hline
\end{tabular}

Table 3: Dependence of the tune on the gradient of the quadrupoles listed in Table 2 in the FODO16 ring. 


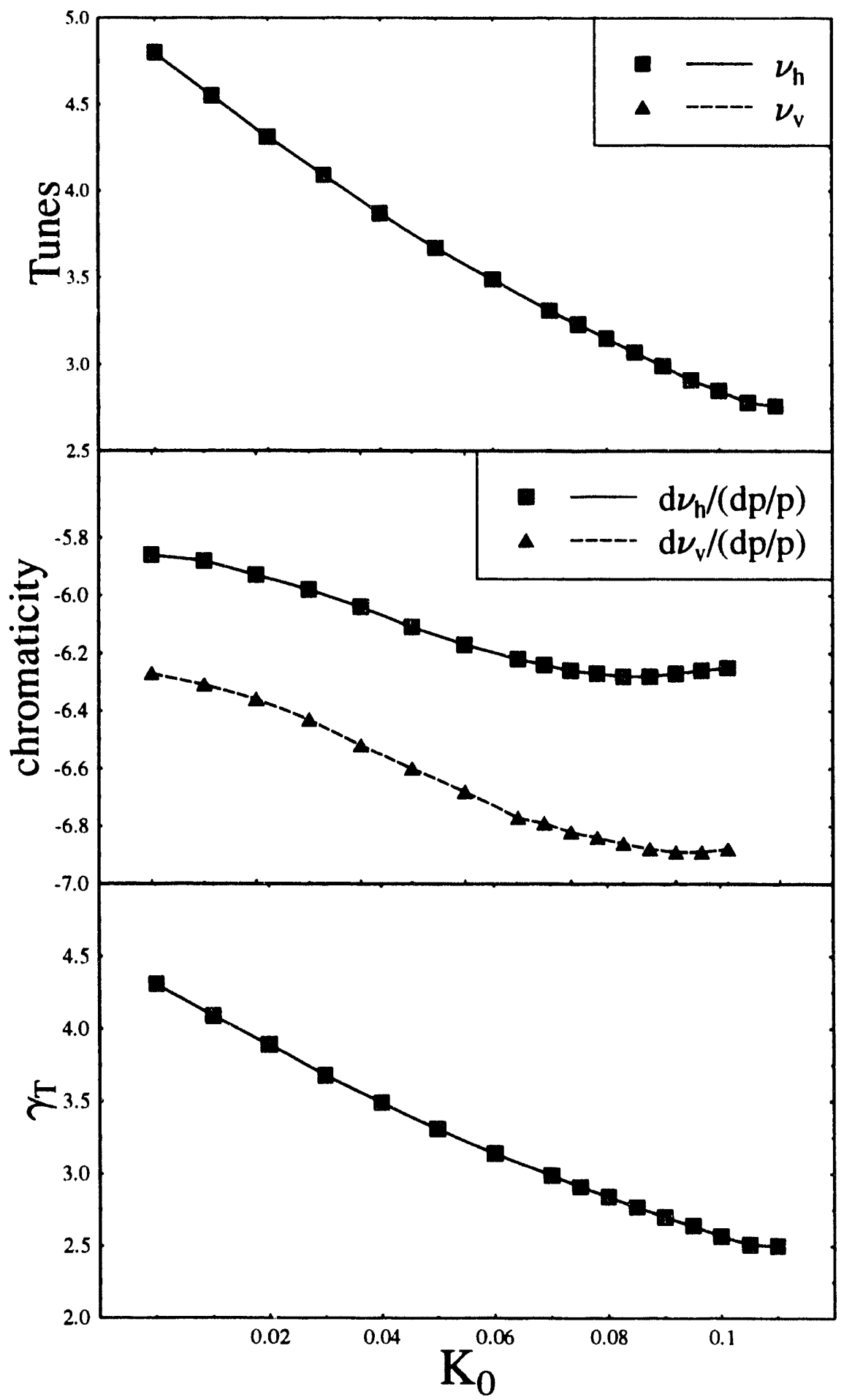

(a)

(b)

(c)

Figure 2: Characteristics of the FODO16 ring; tune per cell is 0.30 . a) shows the change in tune, b) shows the chromaticity and c) shows $\gamma_{T}$ as a function of the space charge. 


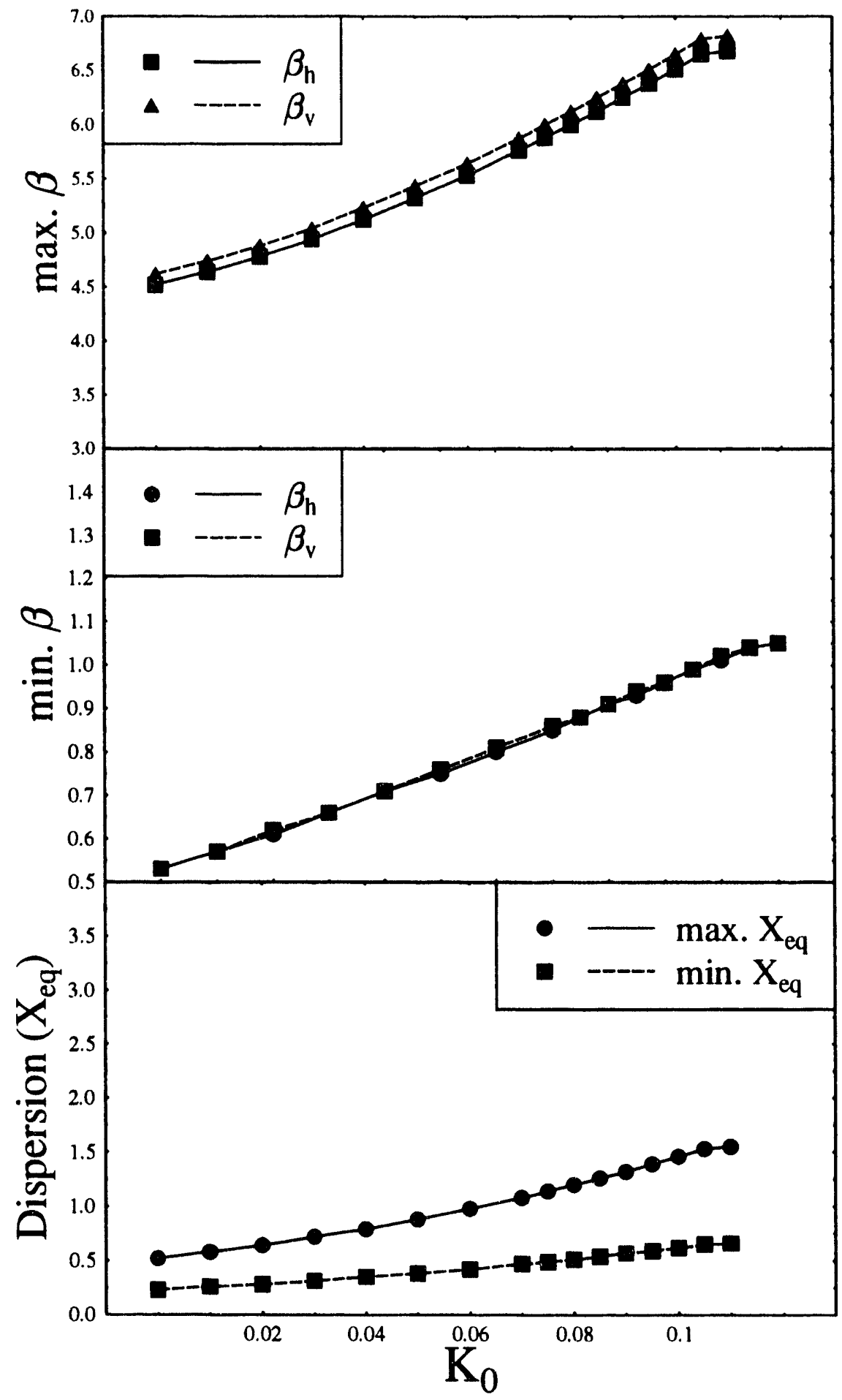

(d)

(e)

(f)

Figure 3: Characteristics of the FODO16 ring; tune per cell is 0.30 . d) shows the maximum $\beta$, e) shows the minimum $\beta$ in the ring and f) shows the dispersion as a function of the space charge. 


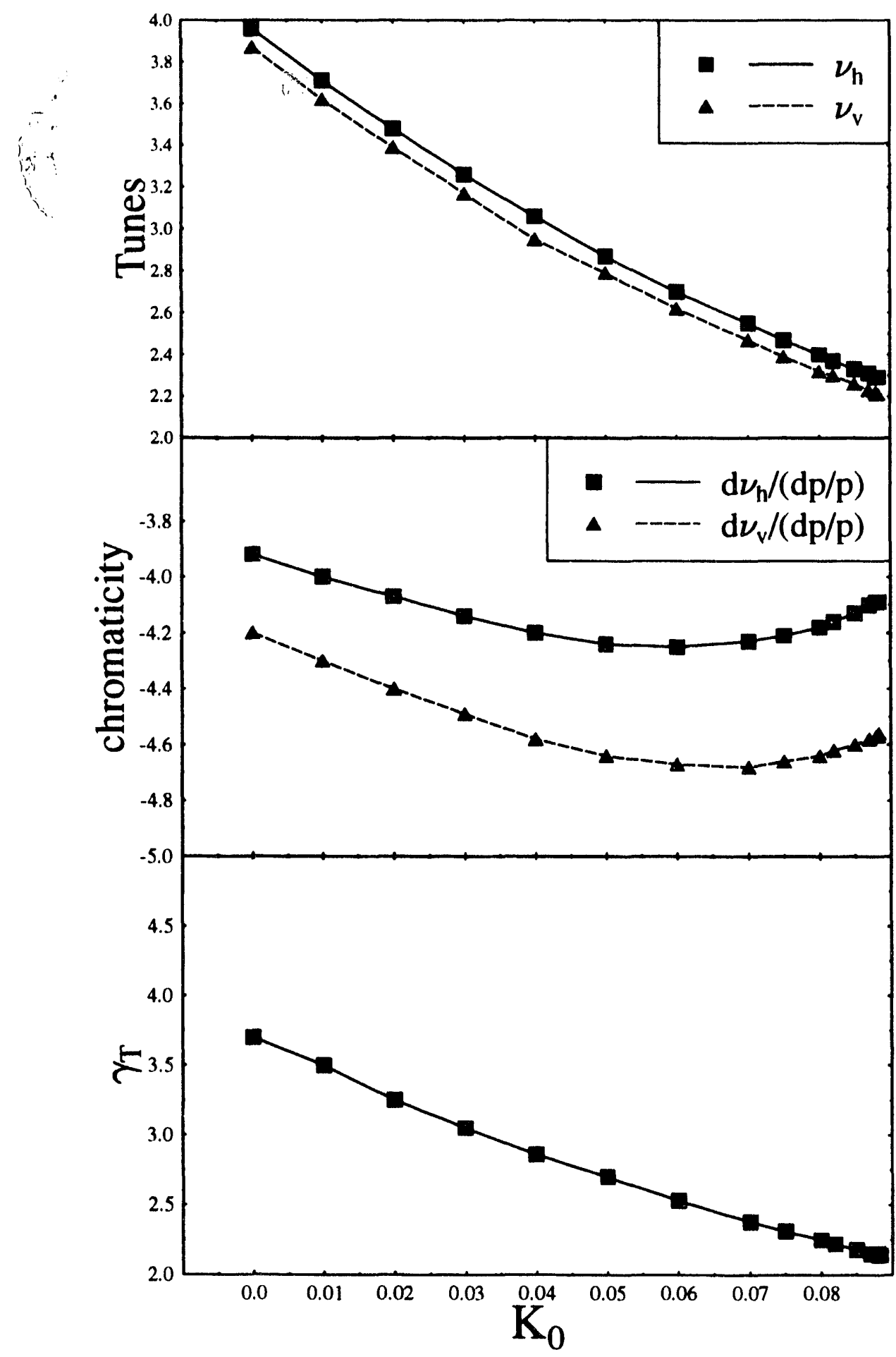

(a)

(b)

(c)

Figure 4: Characteristics of the FODO16 ring; tune per cell is 0.25 . 
Study of the effect of space charge using SYNCH

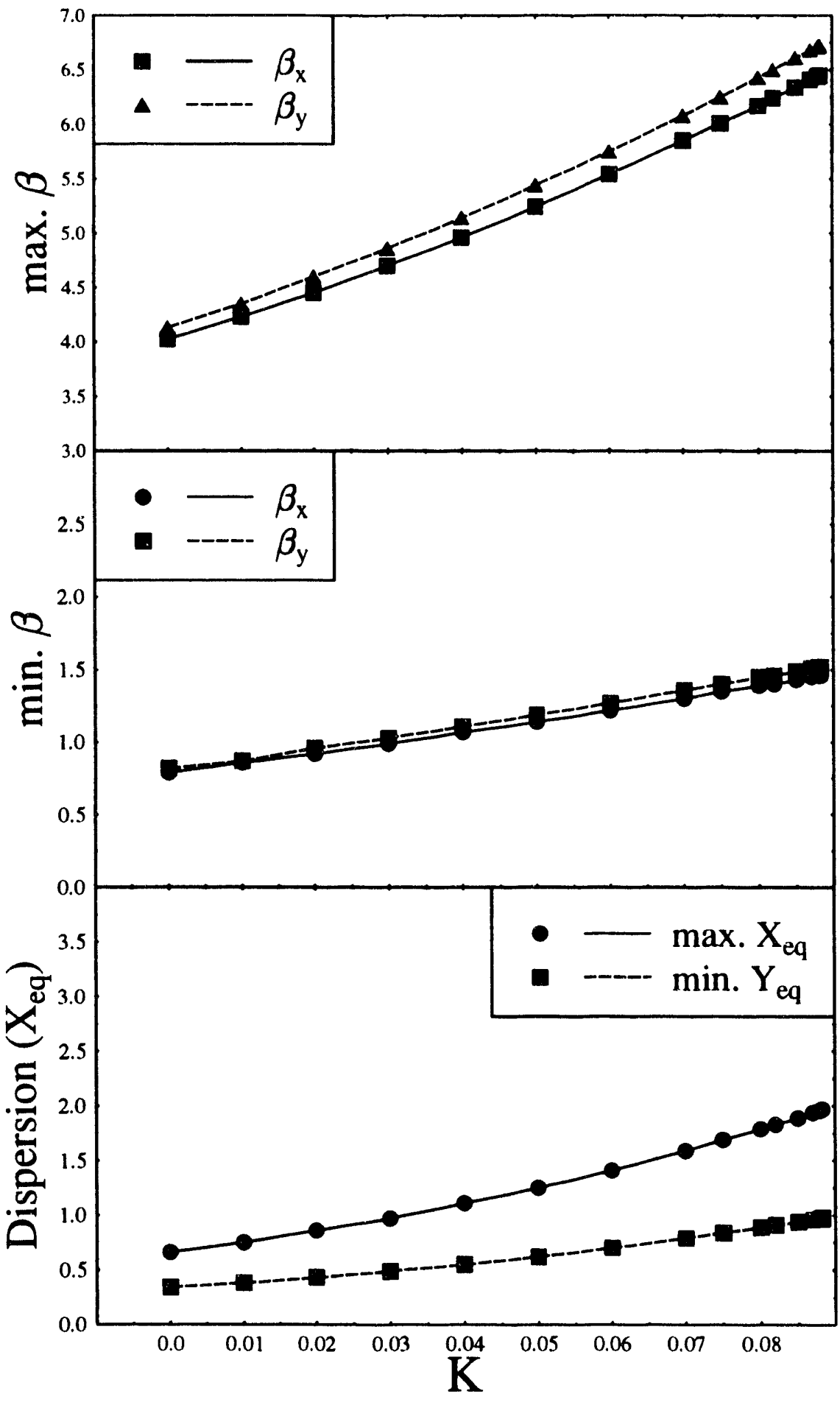

(d)

(e)

(f)

Figure 5: Characteristics of the FODO16 ring; tune per cell is 0.25 . 


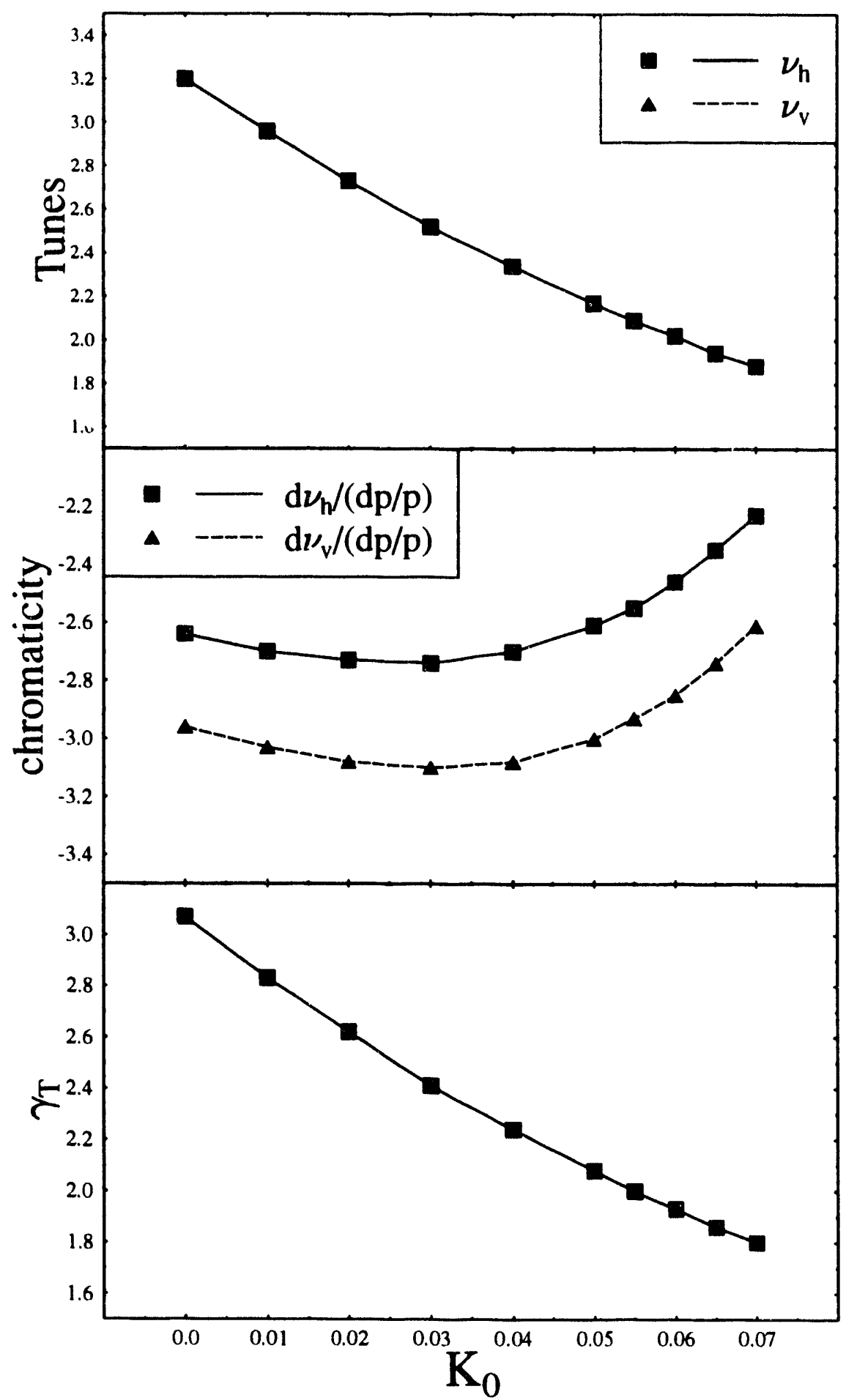

(a)

(b)

(c)

Figure 6: Characteristics of the FODO16 ring; tune per cell is 0.20 . 
Study of the effect of space charge using SYNCH

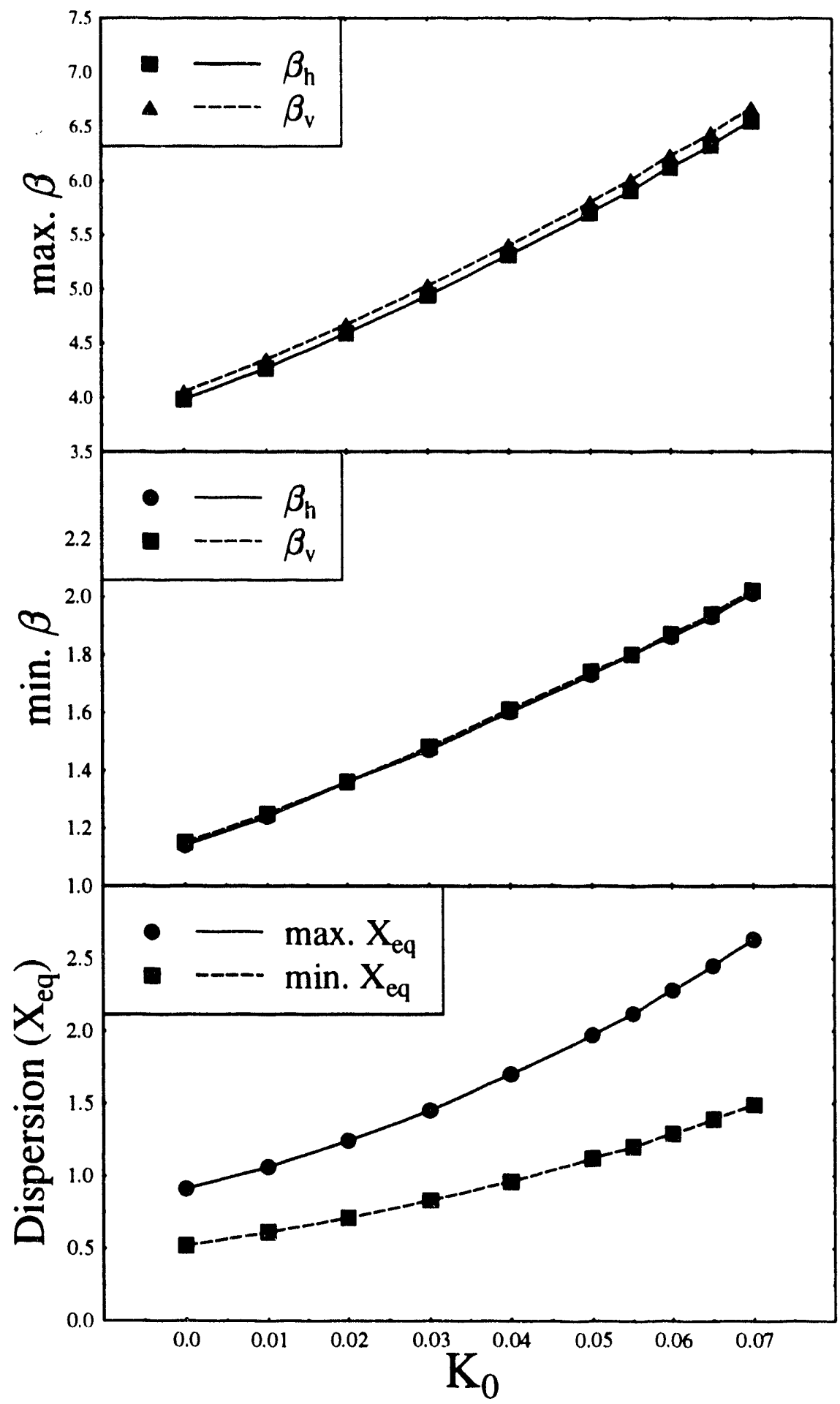

(d)

(e)

(f)

Figure 7: Characteristics of the FODO16 ring; tune per cell is 0.20. 


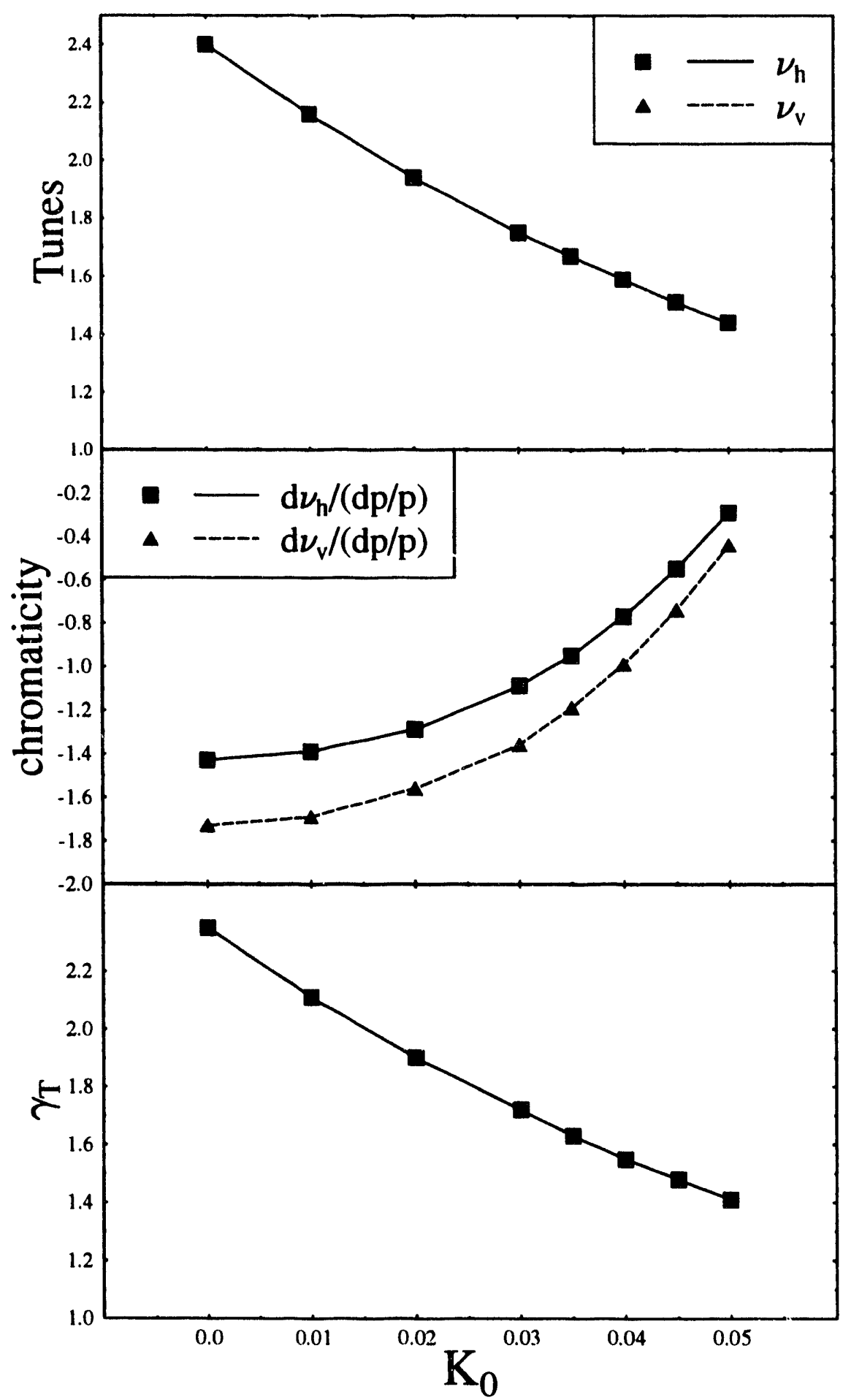

(a)

(b)

(c)

Figure 8: Characteristics of the FODO16 ring; tune per cei' is 0.15 . 


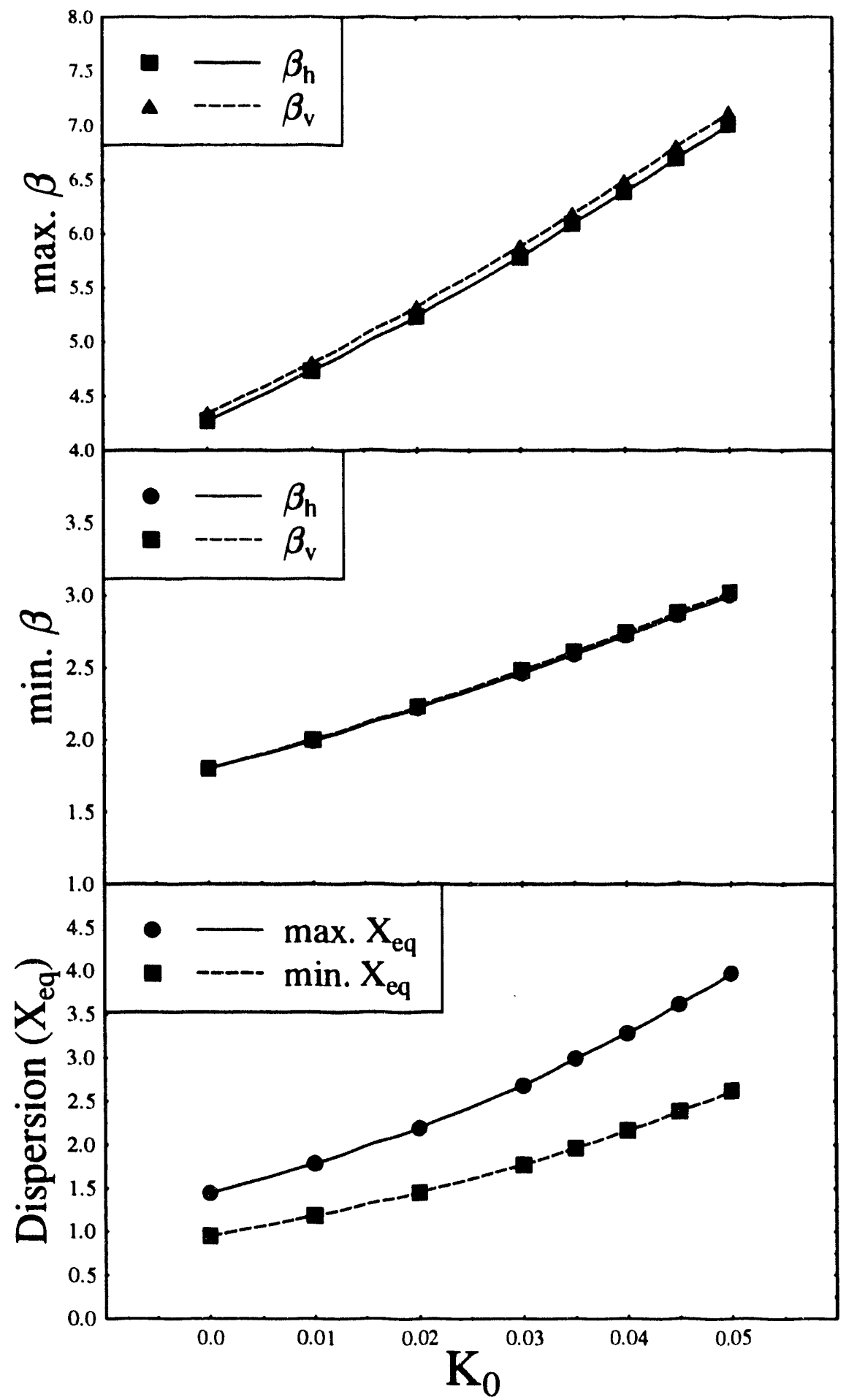

(d)

(e)

(f)

Figure 9: Characteristics of the FODO16 ring; tune per cell is 0.15. 


\begin{tabular}{|c|c|c|c|}
\hline \multicolumn{4}{|c|}{ Magnetic rigidity $B \rho=6.59152 \mathrm{Tm}$} \\
\hline name & type & $\begin{array}{l}\text { length } \\
{[\mathrm{m}]}\end{array}$ & $\begin{array}{c}\mathrm{B} \\
{[\mathrm{T}]}\end{array}$ \\
\hline $\mathrm{L}$ & drift & 1.01509 & $\mathrm{~N} / \mathrm{A}$ \\
\hline$S$ & drift & 0.12688 & $\mathrm{~N} / \mathrm{A}$ \\
\hline D & quad & ? 12689 & $\mathrm{~N} / \mathrm{A}$ \\
\hline $\mathrm{F}$ & quad & 0.12689 & $\mathrm{~N} / \mathrm{A}$ \\
\hline B & dipole & 0.76132 & 1.7 \\
\hline \multicolumn{4}{|c|}{ Beamline C : F S B S D } \\
\hline \multicolumn{4}{|c|}{ D S B S F } \\
\hline \multicolumn{4}{|c|}{ Beamline CE : F L D D L F } \\
\hline \multicolumn{4}{|c|}{ Beamline HSP : CE C C } \\
\hline \multicolumn{4}{|c|}{ Cycle $=-4 \mathrm{HSP}$} \\
\hline \multicolumn{4}{|c|}{ Circumference : $60.91 \mathrm{~m}$} \\
\hline
\end{tabular}

Table 4: Parameters for the FODO4 ring.

\begin{tabular}{||c|c|c|c||}
\hline $\begin{array}{c}\text { tune } \\
\text { per cell }\end{array}$ & $\begin{array}{c}\text { Tune } \\
\text { Total }\end{array}$ & $\begin{array}{c}\text { Gradient } \\
\text { F [Tm] }\end{array}$ & $\begin{array}{c}\text { Gradient } \\
\text { D [Tm] }\end{array}$ \\
\hline $0.2416 \ldots$ & 5.8 & 29.36352 & -30.0938 \\
\hline 0.20 & 4.8 & 24.79413 & -25.5521 \\
\hline 0.15 & 3.6 & 18.48649 & -19.3618 \\
\hline
\end{tabular}

Table 5: Dependence of the tune on the gradient of the quadrupoles listed iil Table 4. 


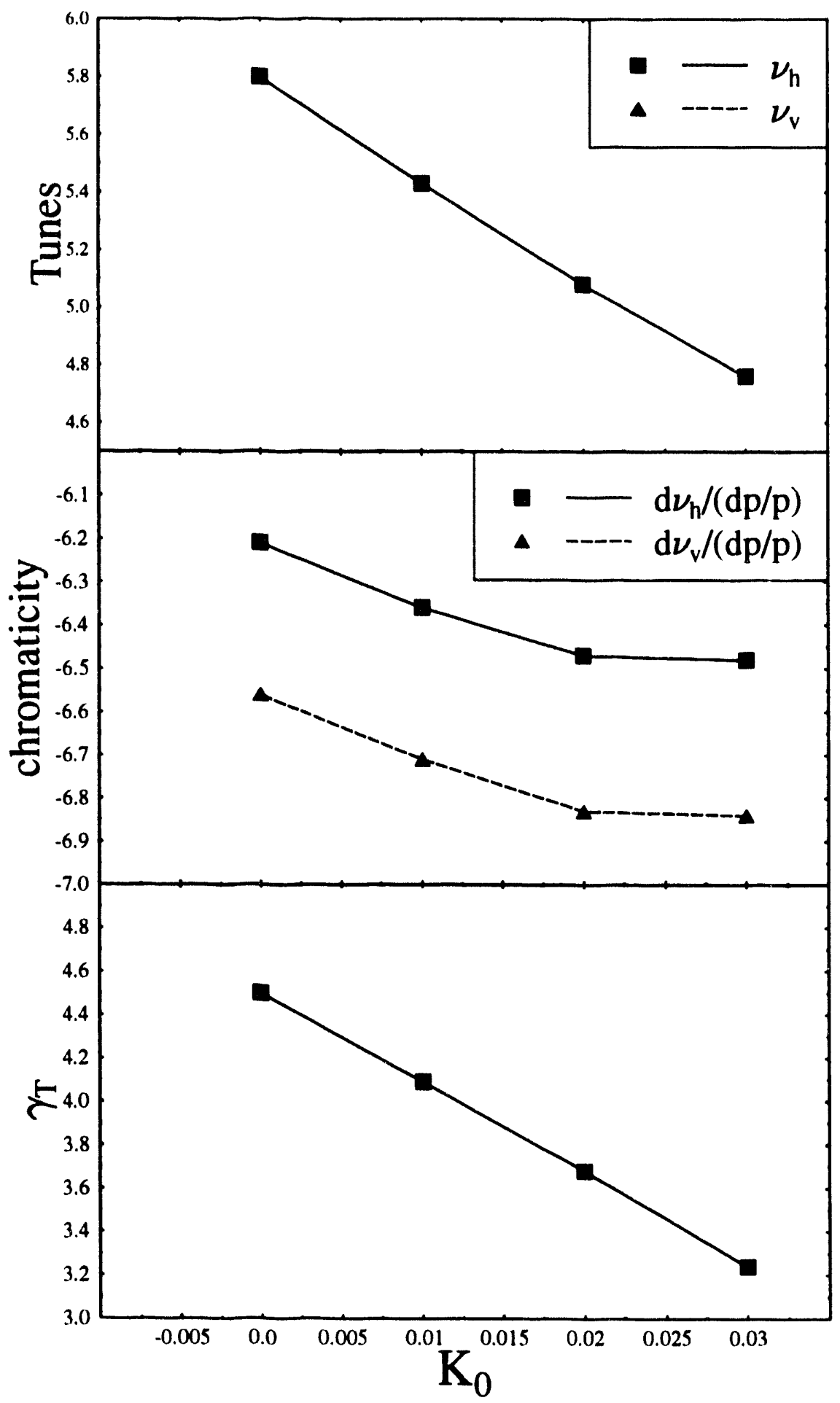

(a)

(b)

(c)

Figure 10: Characteristics of the FODO4 ring; the total tune is 5.80 . 


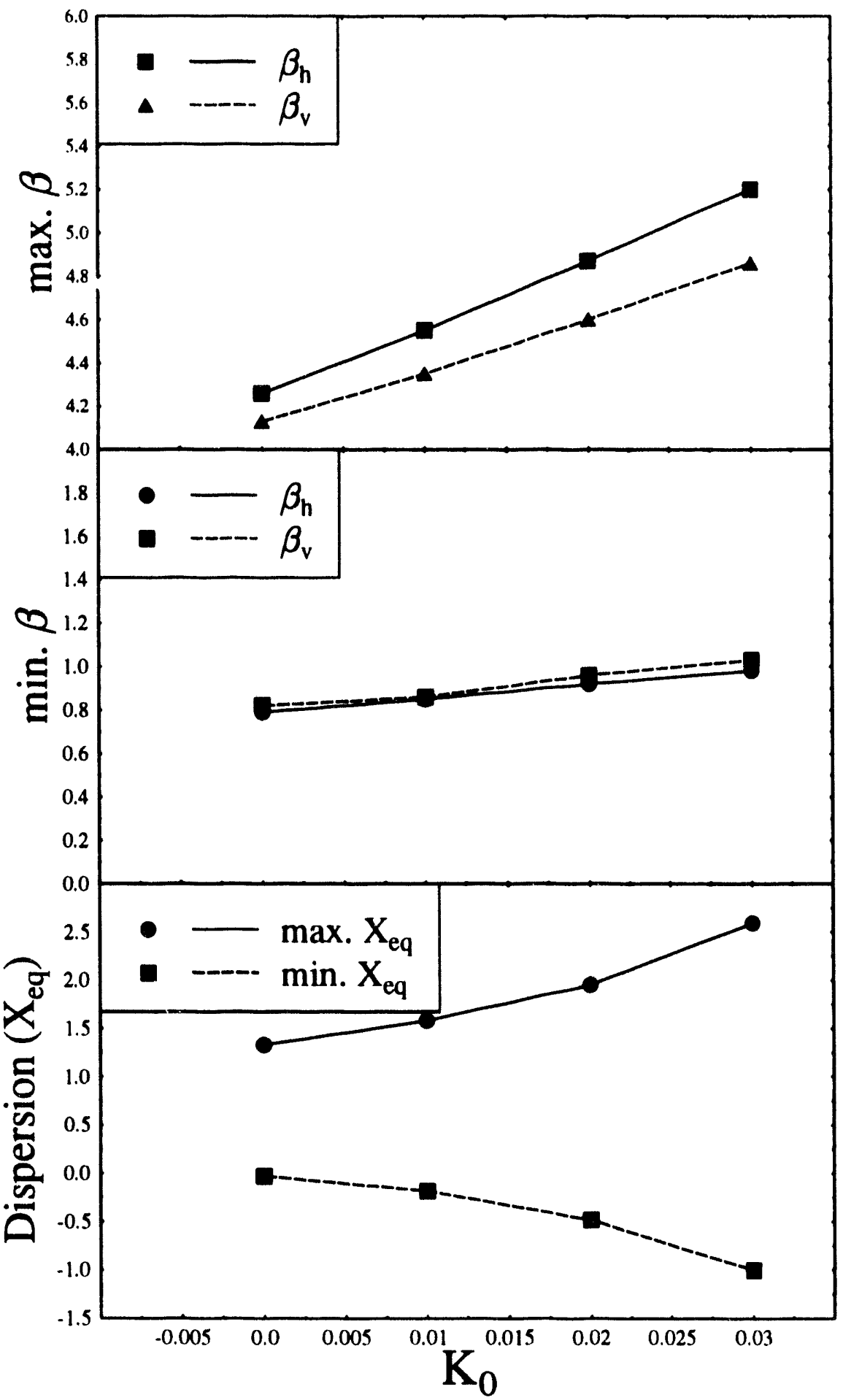

(d)

(e)

(f)

Figure 11: Characteristics of the FODO4 ring; the total tune is 5.80 . 


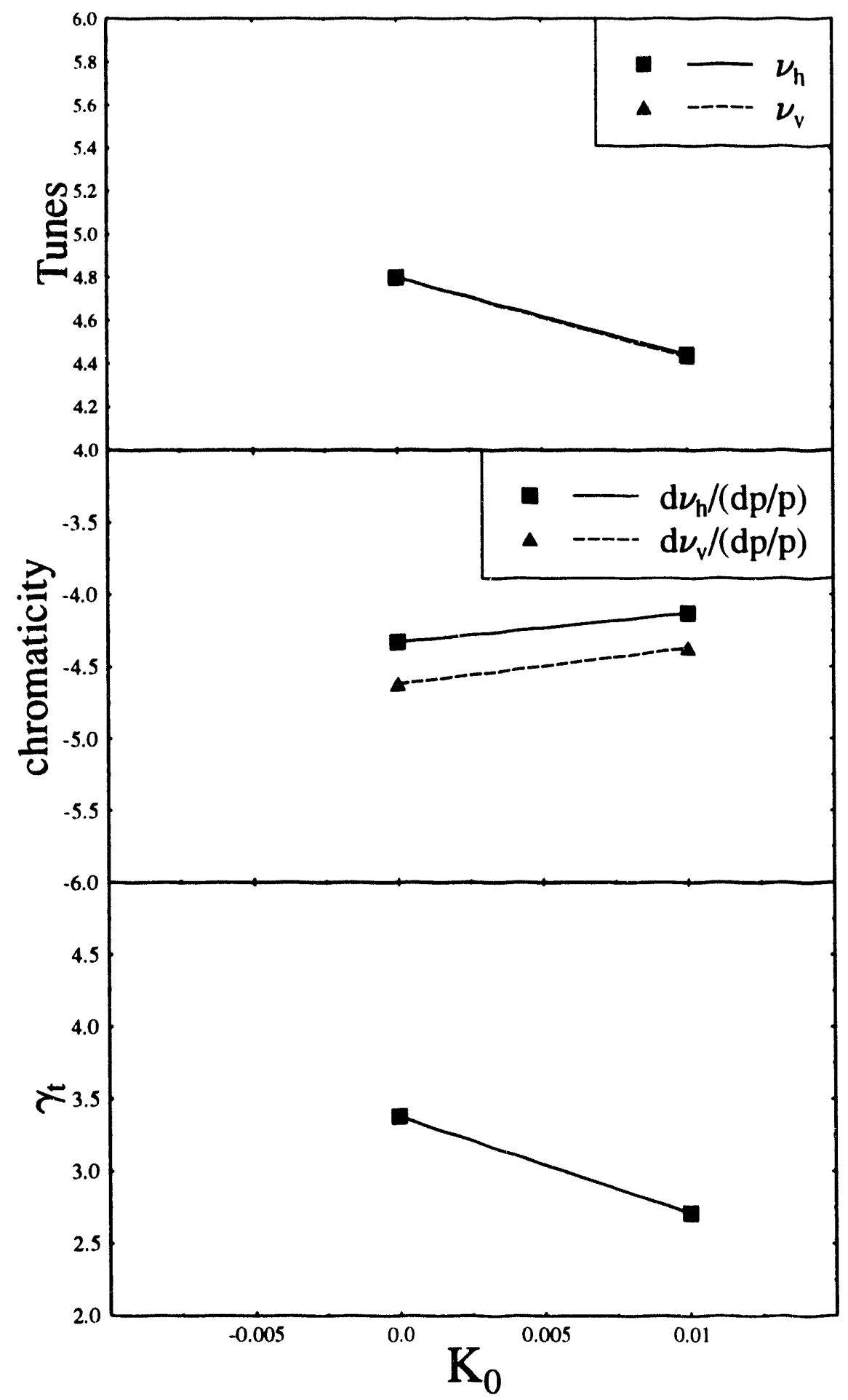

(a)

(b)

(c)

Figure 12: Characteristics of the FODO4 ring; the total tune is 4.80 . 


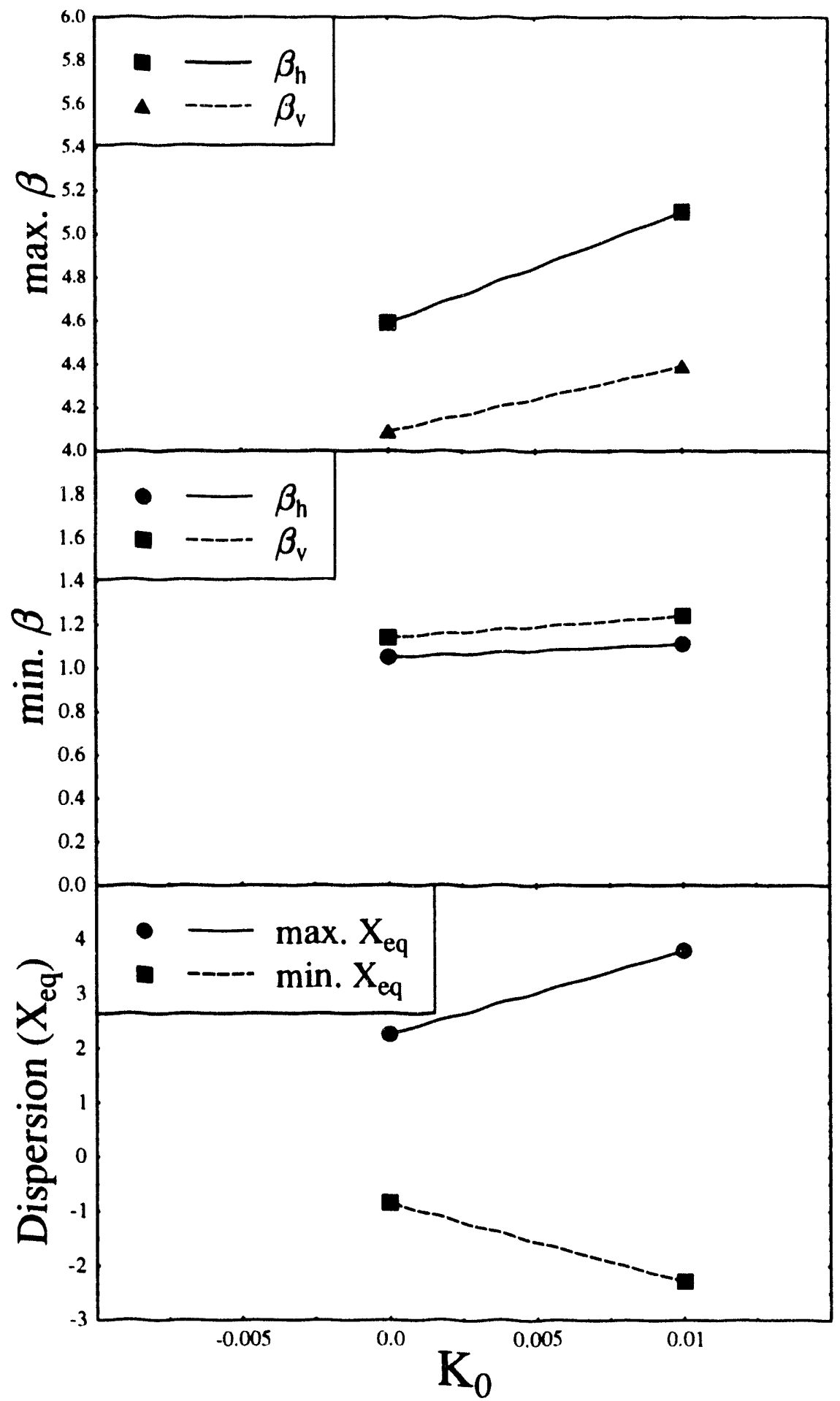

(d)

(e)

(f)

Figure 13: Characteristics of the FODO4 ring; the total tune is 4.80 . 


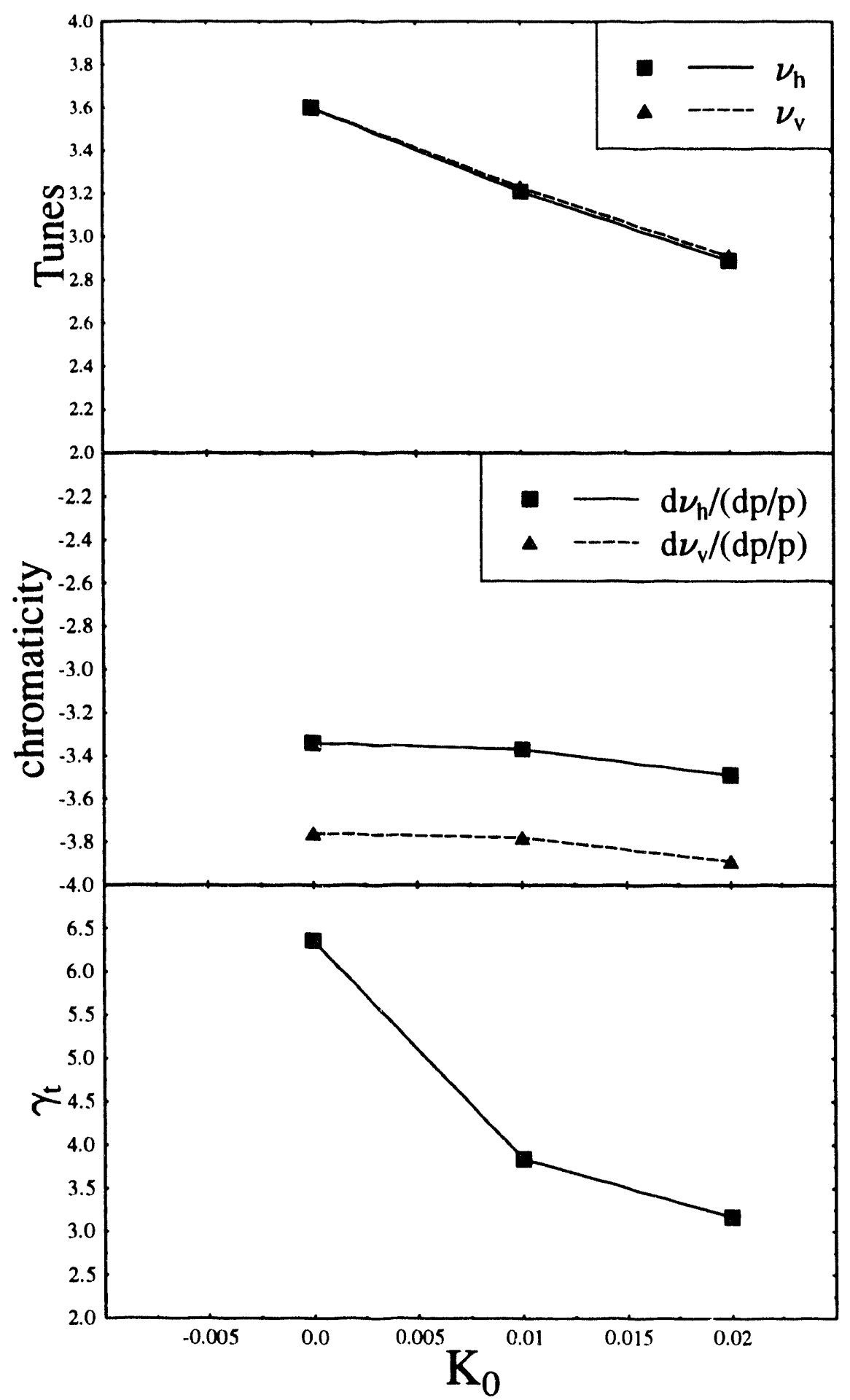

(a)

(b)

(c)

Figure 14: Characteristics of the FODO4 ring; the total tune is 3.60 . 


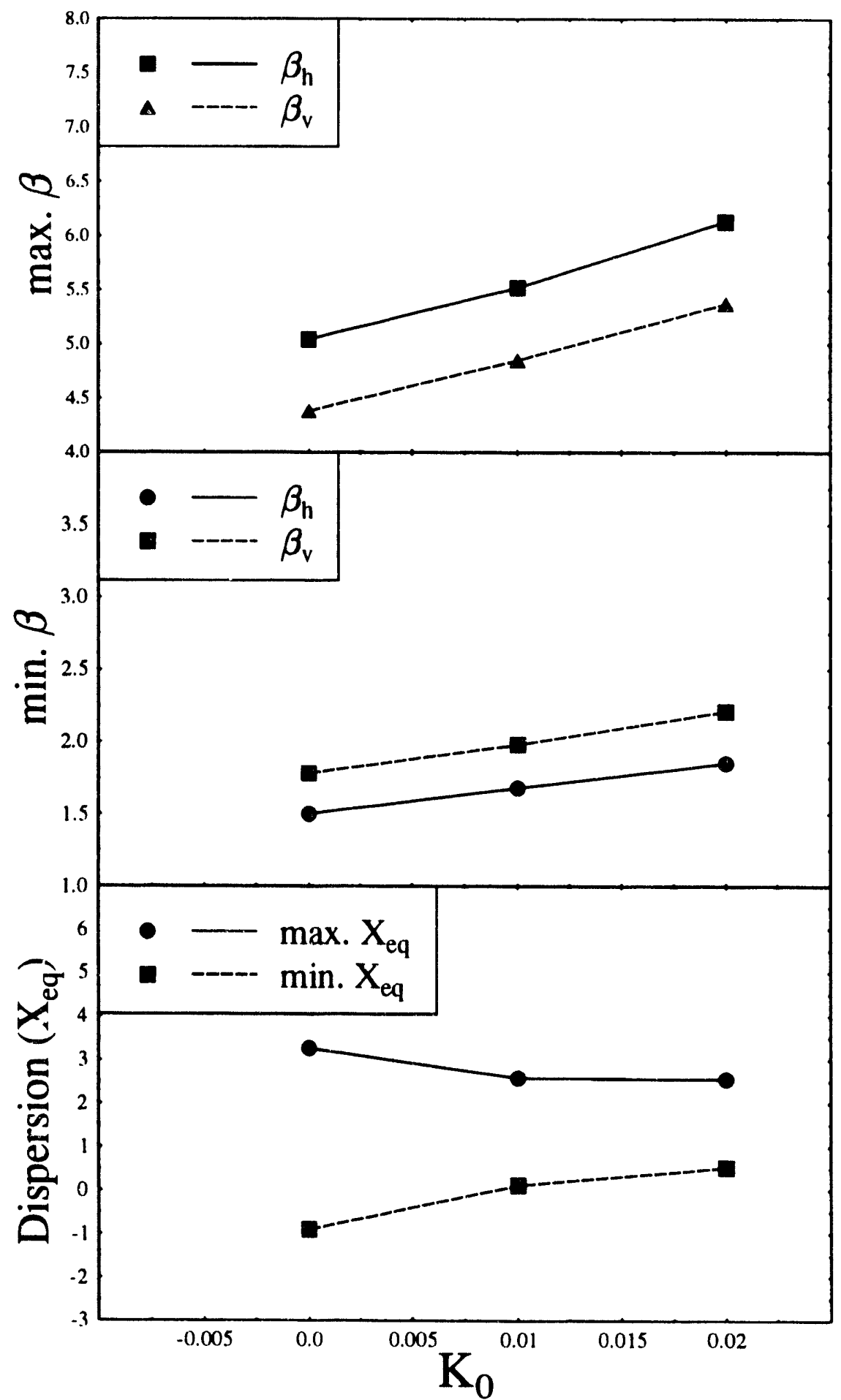

(d)

(e)

(f)

Figure 15: (haracteristics of the FODO4 ring; the total tune is 3.60 . 


\begin{tabular}{||c|c|c|c||}
\hline \multicolumn{4}{||l|}{ Magnetic rigidity $B \rho=6.59152 \mathrm{Tm} . \mid$} \\
\hline name & type & $\begin{array}{c}\text { length } \\
{[\mathrm{m}]}\end{array}$ & $\begin{array}{c}\mathrm{B} \\
{[\mathrm{T}]}\end{array}$ \\
\hline $\mathrm{L}$ & drift & 1.01509 & $\mathrm{~N} / \mathrm{A}$ \\
\hline $\mathrm{D}$ & drift & 0.12688 & $\mathrm{~N} / \mathrm{A}$ \\
\hline $\mathrm{F}$ & quad & 0.12689 & $\mathrm{~N} / \mathrm{A}$ \\
\hline $\mathrm{B}$ & quad & 0.12689 & $\mathrm{~N} / \mathrm{A}$ \\
\hline dipole & 0.76132 & 1.7 \\
\hline \multicolumn{4}{|c||}{$\mathrm{D} \mathrm{S} \mathrm{B} \mathrm{S} \mathrm{F}$} \\
\hline Beamline C : F S B S D \\
\hline Beamline HSP : C CE \\
\hline Cycle = -8 HSP \\
\hline Circumference : $60.91 \mathrm{~m}$ \\
\hline
\end{tabular}

Table 6: Parameters for the FODO8 ring.

\begin{tabular}{||c|c|c|c||}
\hline $\begin{array}{c}\text { tune } \\
\text { per cell }\end{array}$ & $\begin{array}{c}\text { Tune } \\
\text { Total }\end{array}$ & $\begin{array}{c}\text { Gradient } \\
\text { F [Tm] }\end{array}$ & $\begin{array}{c}\text { Gradient } \\
\text { D [Tm] }\end{array}$ \\
\hline 0.30 & 7.2 & 34.82908 & -35.5052 \\
\hline 0.25 & 6.0 & 30.21436 & -30.9372 \\
\hline
\end{tabular}

Table 7: Dependence of the tune on the gradient of the quadrupoles listed in Table 6. 


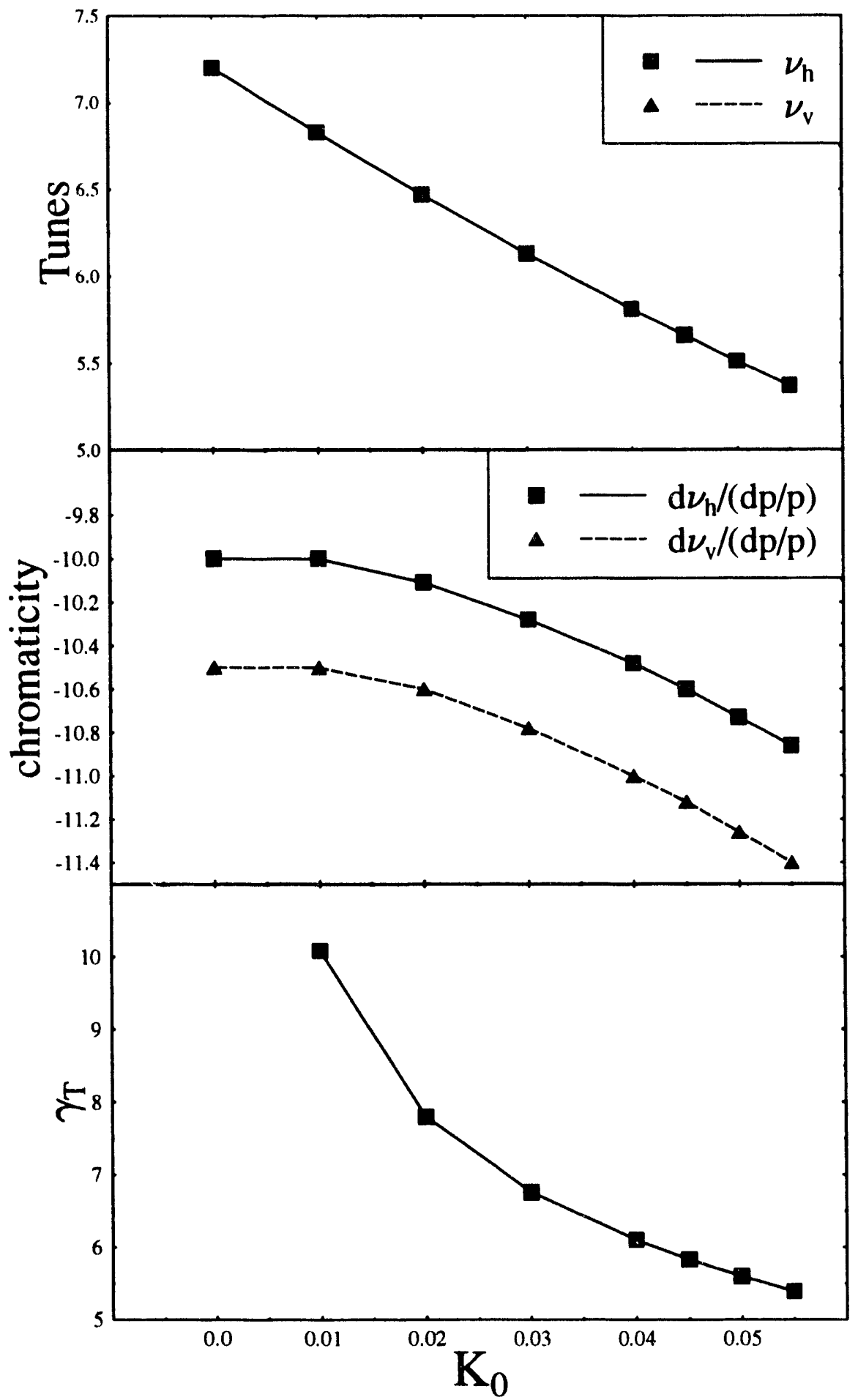

(a)

(b)

(c)

Figure 16: Characteristics of the FODO 8 ring; the total tune is 7.20 . 


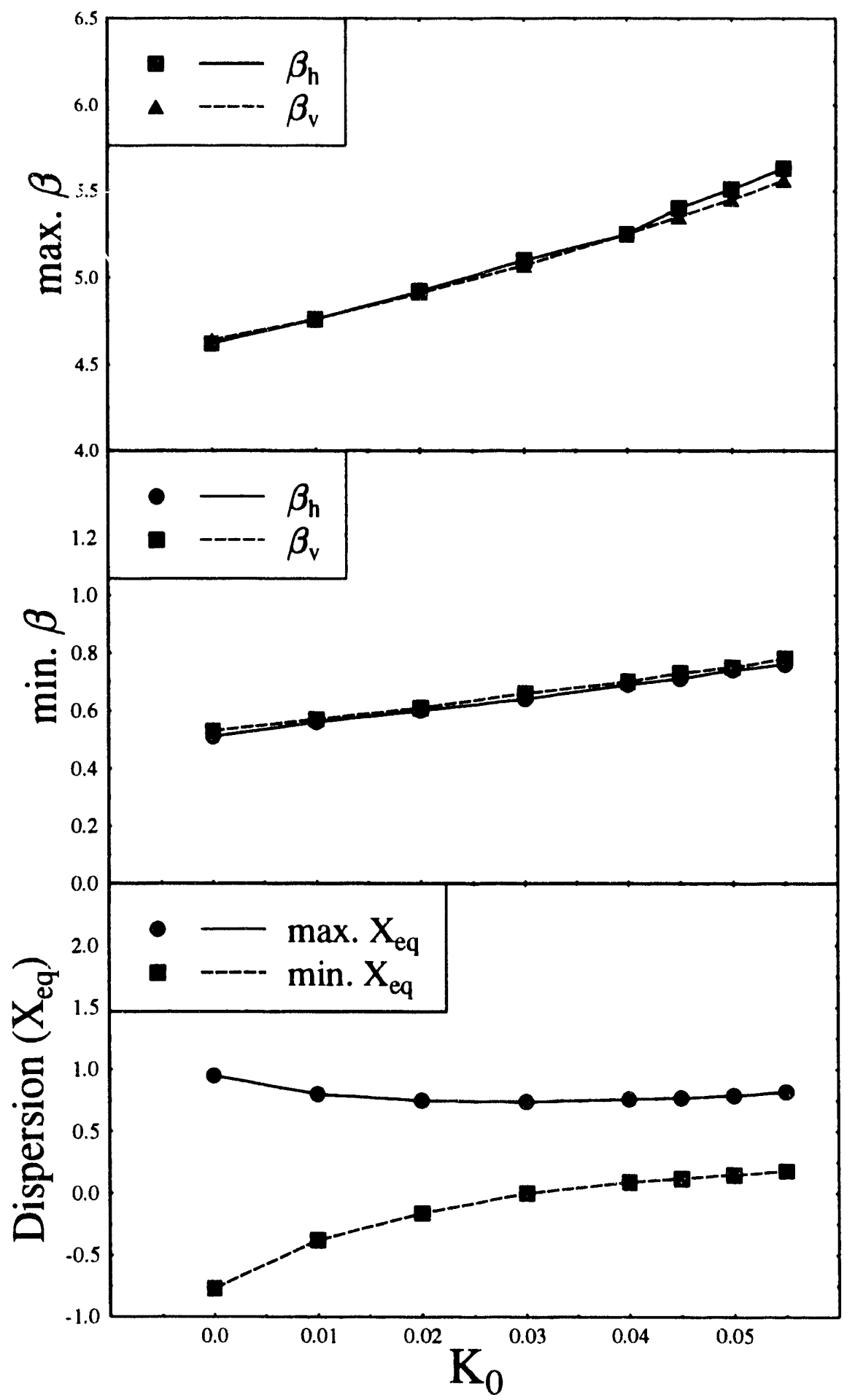

(d)

(e)

(f)

Figure 17: Characteristics of the FODO 8 ring; the total tune is 7.20 . 


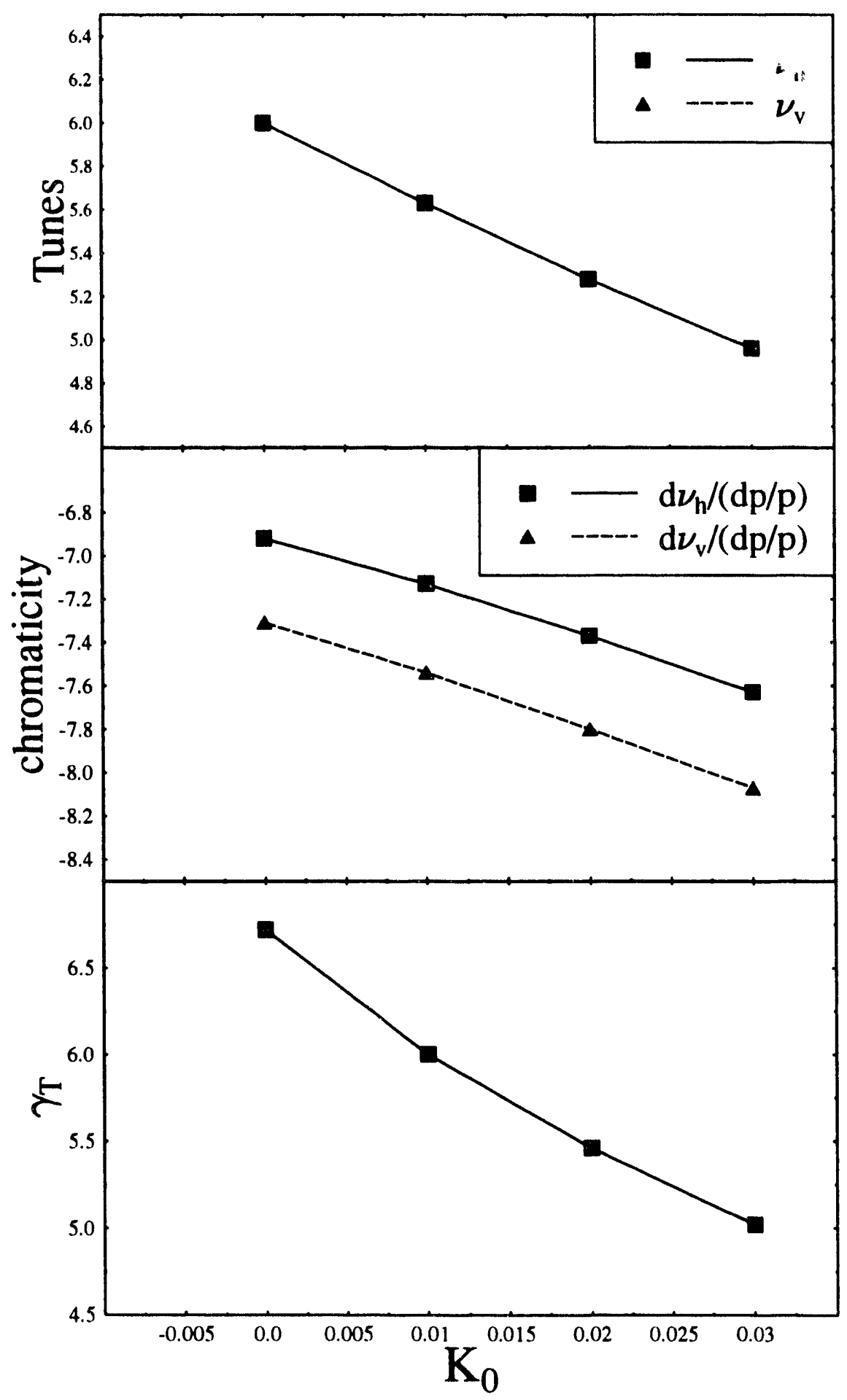

(a)

(b)

(c)

Figure 18: Characteristics of the FODO8 ring; the total tune is 6.0 


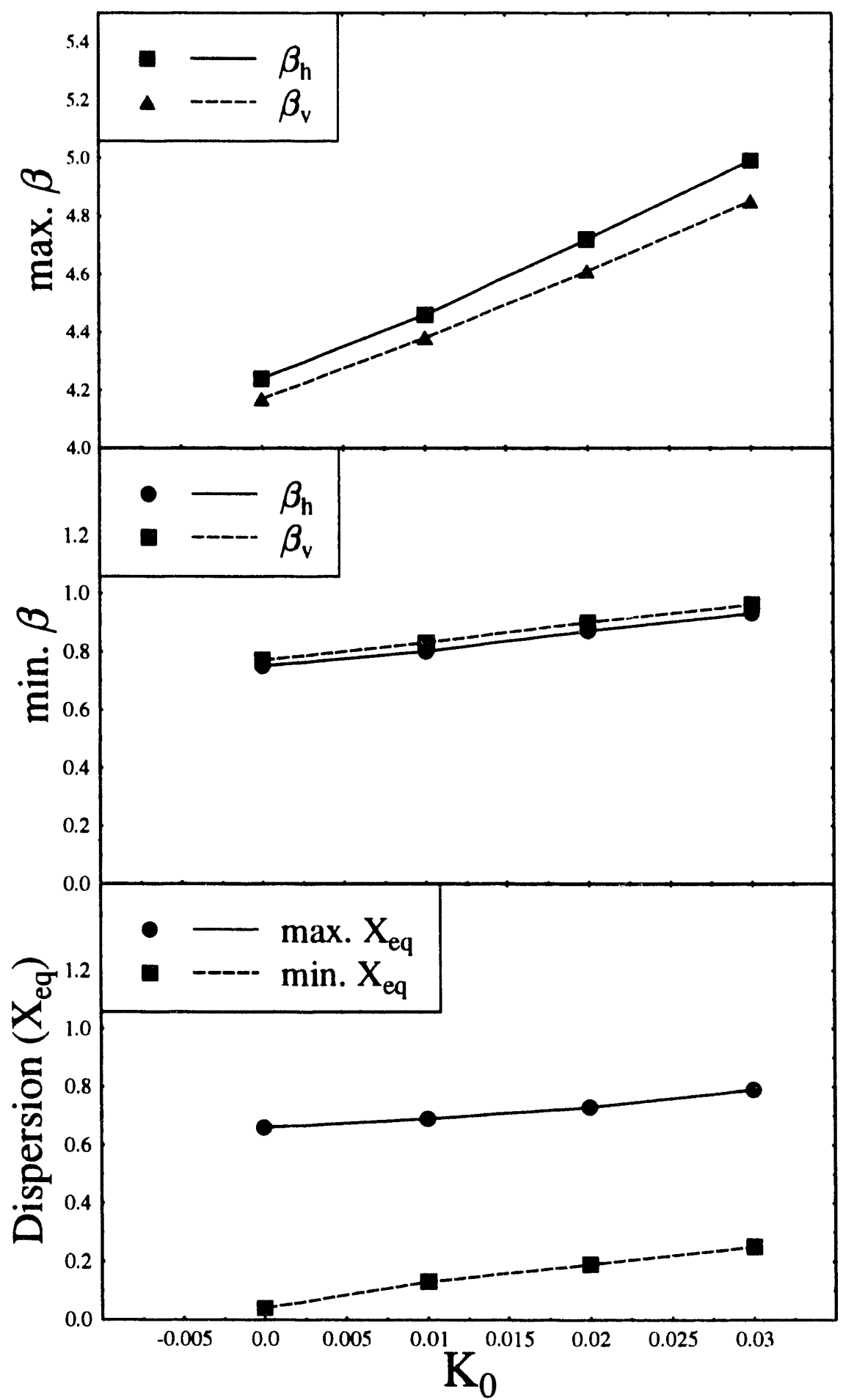

(d)

(e)

(f)

Figure 19: Characteristics of the FODO8 ring; the total tune is 6.0 


\begin{tabular}{|c|c|c|c|c|}
\hline \multicolumn{5}{|c|}{ Magnetic rigidity $B \rho=6.59152 \mathrm{Tm}$. } \\
\hline name & type & $\begin{array}{c}\text { length } \\
{[\mathrm{m}]}\end{array}$ & $\begin{array}{c}\mathrm{B} \\
{[\mathrm{T}]}\end{array}$ & $\begin{array}{c}\mathrm{G} \\
{[\mathrm{T} / \mathrm{m}]}\end{array}$ \\
\hline L & drift & 2.03018 & $\mathrm{~N} / \mathrm{A}$ & $\mathrm{N} / \mathrm{A}$ \\
\hline$S$ & drift & 0.12689 & $\mathrm{~N} / \mathrm{A}$ & $\mathrm{N} / \mathrm{A}$ \\
\hline Q1 & quad & 0.12689 & $\mathrm{~N} / \mathrm{A}$ & -61.3 \\
\hline Q2 & quad & 0.12689 & $\mathrm{~N} / \mathrm{A}$ & 59.2 \\
\hline Q3 & quad & 0.12689 & $\mathrm{~N} / \mathrm{A}$ & -46.7 \\
\hline Q4 & quad & 0.12689 & $\mathrm{~N} / \mathrm{A}$ & 40.4 \\
\hline Q5 & quad & 0.12689 & $\mathrm{~N} / \mathrm{A}$ & -28.8 \\
\hline Q6 & quad & 0.12689 & $\mathrm{~N} / \mathrm{A}$ & 43.5 \\
\hline $\mathrm{B}$ & dipole & 0.76132 & 1.7 & $\mathrm{~N} / \mathrm{A}$ \\
\hline \multicolumn{5}{|c|}{ Beamline $\mathrm{C} 2: \mathrm{Q} 6 \mathrm{~S} \mathrm{~B} S \mathrm{~S} 5$} \\
\hline \multicolumn{5}{|c|}{ Q5 S B S Q4 } \\
\hline \multicolumn{5}{|c|}{ Beamline C1: Q4 S B S Q3 } \\
\hline \multicolumn{5}{|c|}{ Q3 S B S Q2 } \\
\hline \multicolumn{5}{|c|}{ Beamline CE : Q2 S Q1 Q1 L } \\
\hline \multicolumn{5}{|c|}{ Cycle $=-4 \mathrm{C} 2 \mathrm{C} / 1 \mathrm{C} \mathrm{E}$} \\
\hline \multicolumn{5}{|c|}{ Circumference : $60.91 \mathrm{~m}$} \\
\hline
\end{tabular}

Table 8: Parameters for the FODO4R ring. 


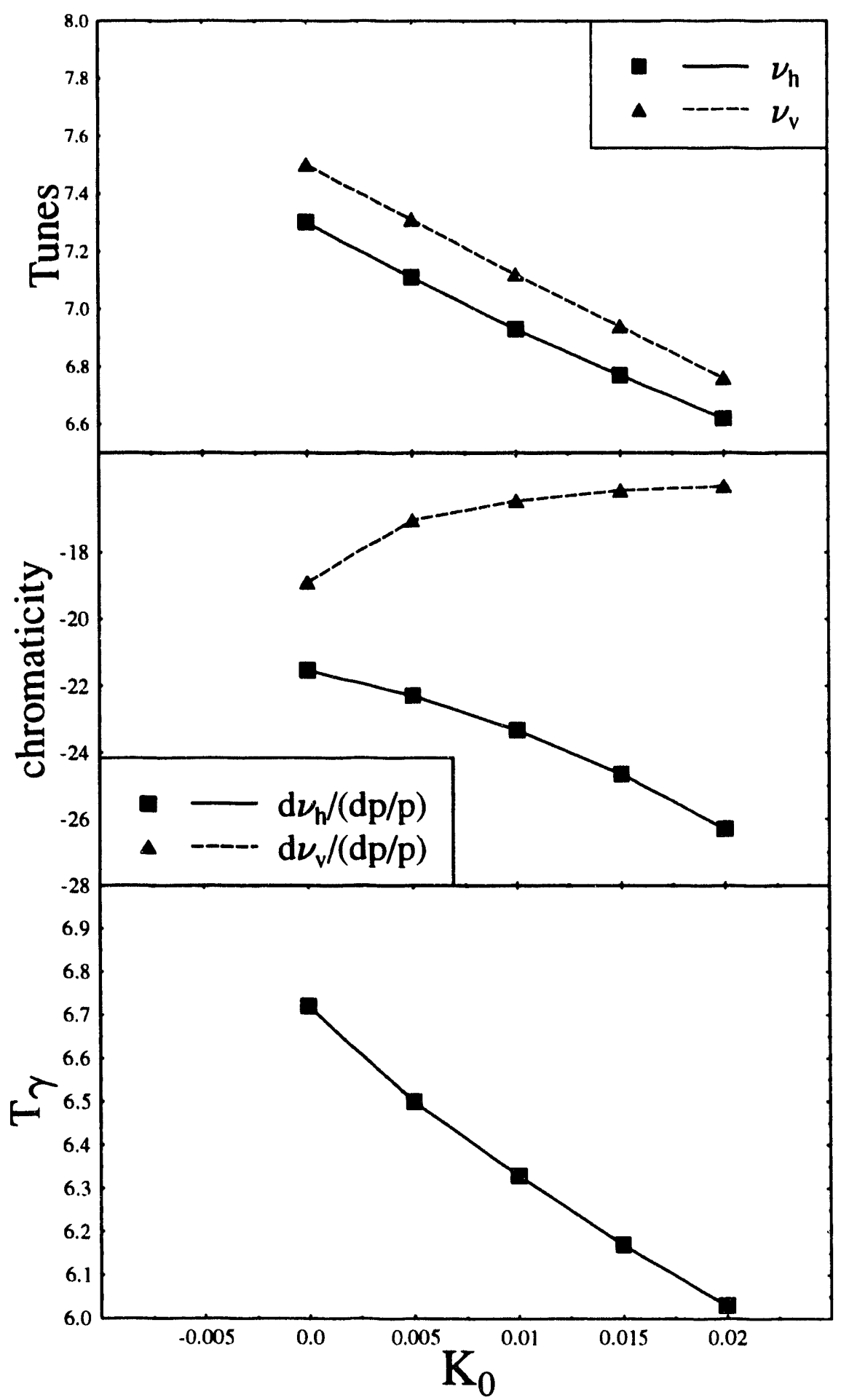

(a)

(b)

(c)

Figure 20: Characteristics of the FODO4R ring; the total tune is 7.2 . 


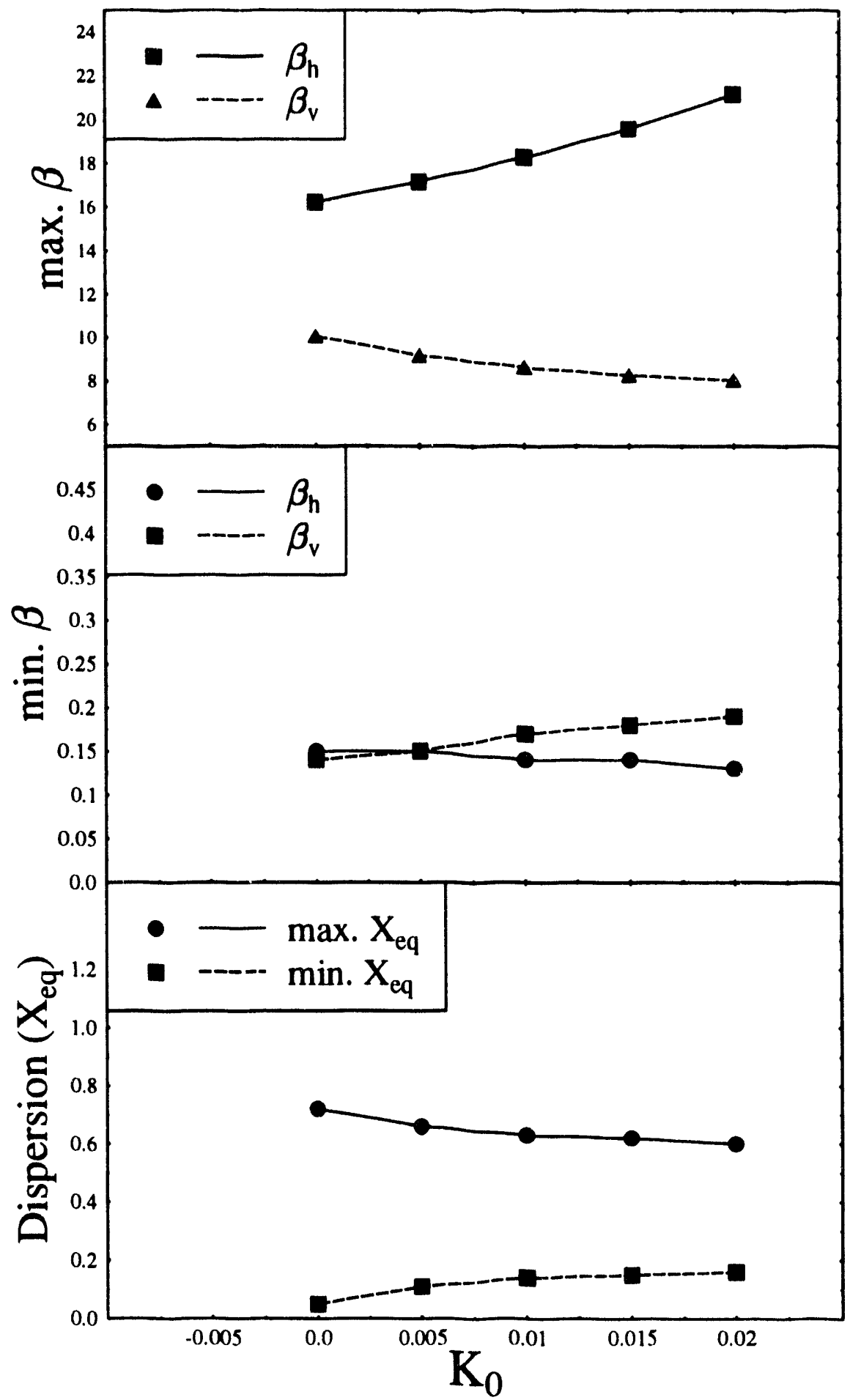

(d)

(e)

(f)

Figure 21: Characteristics of the FODO4R ring; the total tune is 7.2 . 


\begin{tabular}{||c|c|c|c|c||}
\hline \multicolumn{5}{||c||}{ Magnetic rigidity $B \rho=4.2 \mathrm{Tm}}$. \\
\hline name & type & $\begin{array}{c}\text { length } \\
{[\mathrm{m}]}\end{array}$ & $\begin{array}{c}\mathrm{B} \\
{[\mathrm{T}]}\end{array}$ & $\begin{array}{c}\mathrm{G} \\
{[\mathrm{T} / \mathrm{m}]}\end{array}$ \\
\hline $\mathrm{L}$ & drift & 2.0 & $\mathrm{~N} / \mathrm{A}$ & $\mathrm{N} / \mathrm{A}$ \\
\hline $\mathrm{S}$ & drift & 0.4 & $\mathrm{~N} / \mathrm{A}$ & $\mathrm{N} / \mathrm{A}$ \\
\hline $\mathrm{D}$ & quad & 0.125 & $\mathrm{~N} / \mathrm{A}$ & 4.41 \\
\hline F & quad & 0.125 & $\mathrm{~N} / \mathrm{A}$ & -5.5195 \\
\hline $\mathrm{B}$ & dipole & 1.0014 & 1.647059 & $\mathrm{~N} / \mathrm{A}$ \\
\hline Beamline HSP $: \mathrm{L} \mathrm{F} \mathrm{S} \mathrm{D} \mathrm{S} \mathrm{B}$ \\
\hline Cycle = -8 HSP \\
\hline Circumference : $64.82 \mathrm{~m}$ \\
\hline
\end{tabular}

Table 9: Parameters for the CRYSTAL8 ring. 


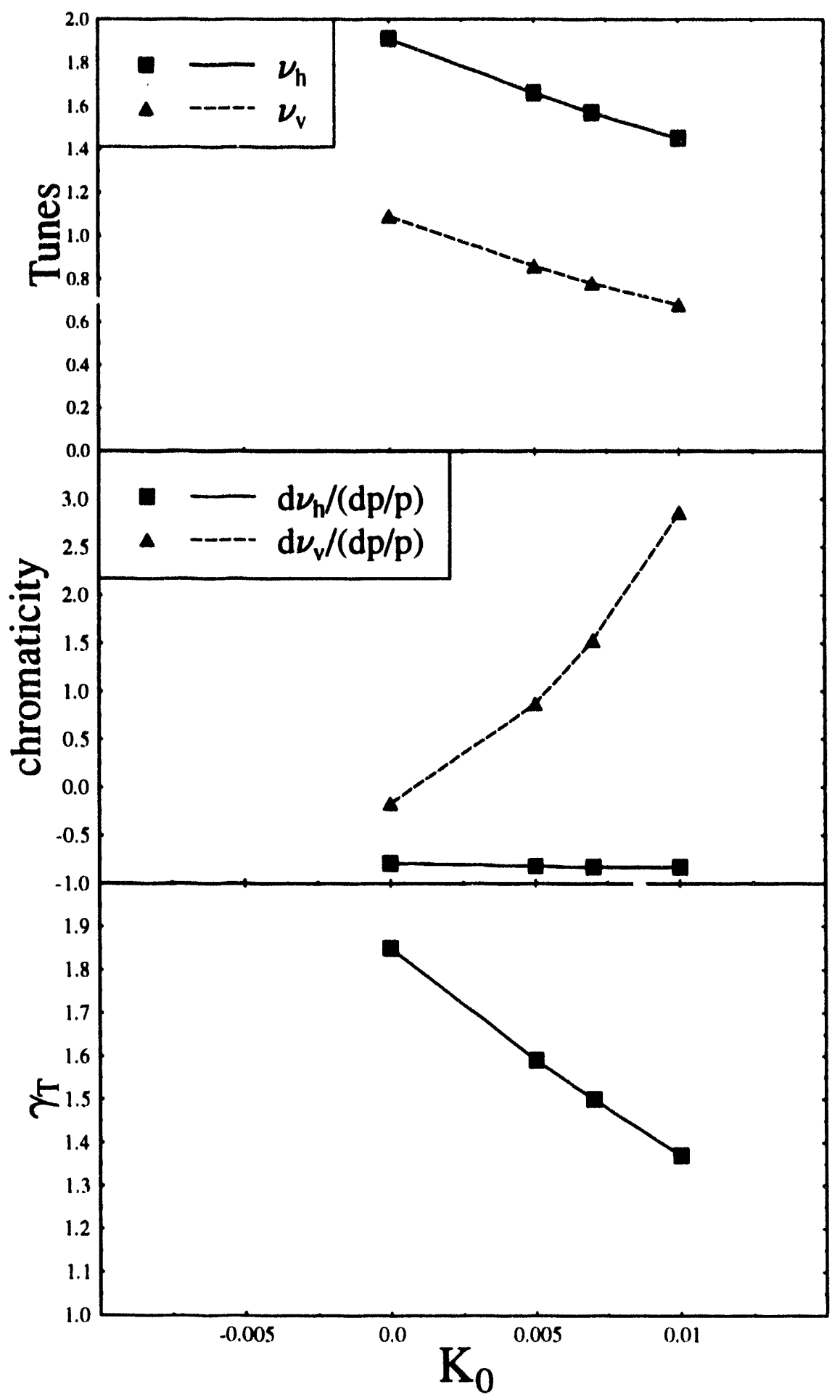

(a)

(b)

(c)

Figure 22: Characteristics of the ('RYSTAL8 ring; the total tunes $\nu_{h}=1.91$ and $\nu_{v}=1.09$. 


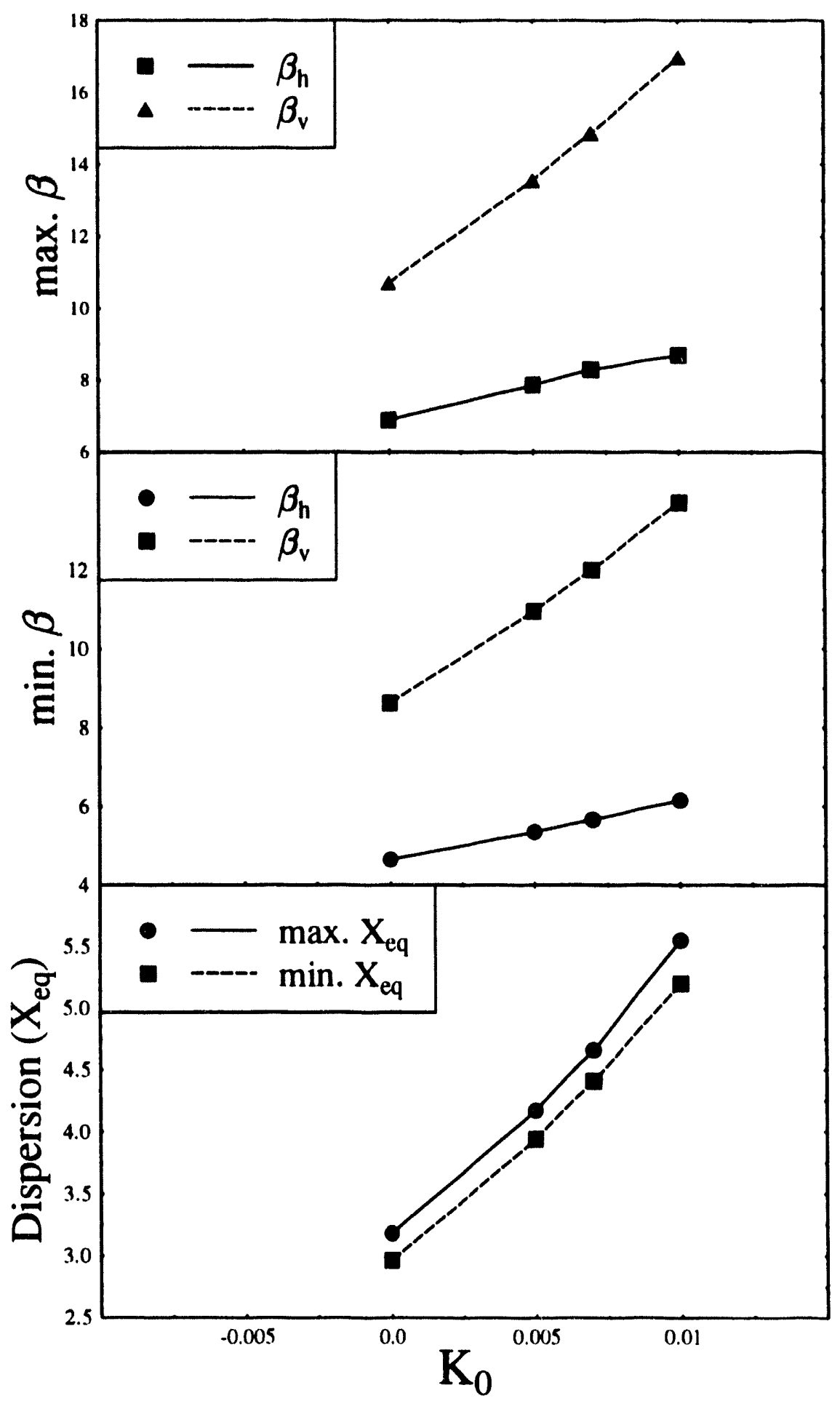

(d)

(e)

(f)

Figure 23: Characteristics of the CRYSTAL8 ring; the total tunes $\nu_{h}=1.91$ and $\nu_{v}=1.09$. 


\section{A Derivation of the Space Charge Per- turbation}

We consider a beam of $N$ particles of charge $Q e$ with uniform longitudinal charge distribution. The charge density is given by:

$$
\rho=N Q e f(s-v t) g(x, y),
$$

which does not depend on the longitudinal coordinate $s$, if

$$
f(s-v t)=f_{0}=\text { constant } .
$$

$f_{0}$ is the inverse of the ring circumference. The function $g(x, y)$ describes the transverse distribution of charge density. We neglect variations with the longitudinal motion, and assume that the transverse motion averages out, so that $g(x, y)$ is time independent. The beam velocity $\mathbf{v}=(0,0, v)$ is constant. The current density in that case is:

$$
\begin{aligned}
& \mathbf{j}=(0,0, j) \\
& j=v \rho=\beta c \rho .
\end{aligned}
$$

In the calculation of the field, we neglect the presence of vacuum chamber or other boundary conditions, as well as the curvature.

The field can be derived from the scalar potential $\mathrm{V}$ and the vector potential $\mathbf{A}=(0,0, A)$. However, in view of $\mathrm{Eq}$. (18) the scalar and vector potential are related:

$$
A=\beta V
$$

as can be ascertained by examining the well known equations for $V$ and $\mathbf{A}[4]$. The electric and the magnetic fields are derived from the scalar potential as follows

$$
\begin{aligned}
& \mathbf{E}=\left(-\frac{\partial V}{\partial x},-\frac{\partial v}{\partial y}, 0\right) \\
& \mathbf{B}=\beta\left(\frac{\partial V}{\partial y},-\frac{\partial V}{\partial x}, 0\right) .
\end{aligned}
$$


The equations of motion follow from the Lorentz equation, where we use $s$ as independent variable:

$$
\begin{aligned}
x^{\prime \prime}+K_{h}(s) x & =-\frac{Q e}{m_{0} c^{2} \beta^{2} \gamma^{3}} \frac{\partial V}{\partial x} \\
y^{\prime \prime}+K_{v}(s) y & =-\frac{Q e}{m_{0} c^{2} \beta^{2} \gamma^{3}} \frac{\partial V}{\partial y}
\end{aligned}
$$

and prime denotes the derivative with respect to $s . K_{h, v}$ are the external focusing functions, $m_{0}$ the rest mass of the particle, and $\beta$ and $\gamma$ the relativistic factors. $V(x, y)$ needs to satisfy Poisson's equation, viz.:

$$
\nabla^{2} V=-4 \pi \rho
$$

We are interested in beams of elliptical cross section, so we change the coordinate set from rectangular $(x, y)$ to elliptical $(r, \psi)$, viz.:

$$
\begin{aligned}
& x=r \cos (\psi), \\
& y=\eta r \sin (\psi) .
\end{aligned}
$$

$\eta$ is aspect ratio of particular ellipse which corresponds to the cross section of the beam. The Laplacian $\nabla^{2}$ has the form:

$$
\begin{array}{r}
\nabla^{2}=f_{1}(\psi) \frac{\partial^{2}}{\partial r^{2}}+f_{2}(\psi) \frac{1}{r} \frac{\partial}{\partial r}+f_{2}(\psi) \frac{1}{r^{2}} \frac{\partial^{2}}{\partial \psi^{2}} \\
+f_{3}(\psi) \frac{1}{r^{2}} \frac{\partial}{\partial \psi}+f_{4}(\psi) \frac{1}{r} \frac{\partial^{2}}{\partial r \partial \psi}
\end{array}
$$

with the functions $f_{i}$ given by:

$$
\begin{aligned}
& f_{1}(\psi)=\frac{1}{\eta^{2}}\left[\eta^{2} \cos ^{2}(\psi)+\sin ^{2}(\psi)\right], \\
& f_{2}(\psi)=\frac{1}{\eta^{2}}\left[\cos ^{2}(\psi)+\eta^{2} \sin ^{2}(\psi)\right], \\
& f_{3}(\psi)=\frac{1}{\eta^{2}}\left(\eta^{2}-1\right) \sin (\psi) \cos (\psi), \\
& f_{4}(\psi)=\frac{2}{\eta^{2}}\left(\eta^{2}-1\right) \sin (\psi) \cos (\psi) .
\end{aligned}
$$


We choose a potential $V$ which does not depend on $\psi$, that is:

$$
f_{1}(\psi) \frac{d^{2} V}{d r^{2}}+f_{2}(\psi) \frac{1}{r} \frac{d V}{d r}=-\pi \rho(r, \psi) .
$$

A consistent solution is then:

$$
V=\frac{1}{2} C r^{2}
$$

where $C$ is a normalization constant. Indeed, by insertion we determine:

$$
\nabla^{2} V=C \cdot \frac{1+\eta^{2}}{\eta},
$$

which is truly independent of $\psi$.

The charge distribution $\rho$ which is consistent with Eq. (3:3) is the uniform distribution

$$
\begin{aligned}
& \rho=\frac{N Q e f_{0}}{\pi \eta a^{2}}, \quad \text { for } r<a, \\
& \rho=0 \text { for } r>a .
\end{aligned}
$$

Inserting Eq. (33) and Eq. (35) in Eq. (32) yields:

$$
C=-\frac{4 N Q e f_{0} / \eta}{a^{2}\left(1+\eta^{2}\right)}
$$

From Eqs. (33) and (36), using the coordinate transformations (25) and (26), we obtain:

$$
\begin{aligned}
& \frac{\partial V}{\partial x}=2 \frac{N Q e f_{0}}{\alpha(\eta) a^{2}} x \\
& \frac{\partial V}{\partial y}=2 \frac{N Q e f_{0}}{\alpha(\eta) b^{2}} y
\end{aligned}
$$

where

$$
\alpha(\eta)=\frac{1}{2}\left(\eta+\frac{1}{\eta}\right)
$$

Finally, taking into account the relation between beam size and emittance:

$$
\begin{aligned}
a^{2} & =\frac{\epsilon_{h}}{\pi} \beta_{h}, \\
b^{2} & =\frac{\epsilon_{v}}{\pi} \beta_{v} .
\end{aligned}
$$


the equations of motion can be rewritten:

$$
\begin{aligned}
& x^{\prime \prime}+K_{h}(s) x-\frac{K}{\beta_{h}} x=0, \\
& y^{\prime \prime}+K_{h}(s) y-\frac{K}{\beta_{v}} y=0 .
\end{aligned}
$$

The space-charge parameter $K$, with $\epsilon_{h}=c_{v}=c$ is given by

$$
K=\frac{2 \pi Q^{2} N f_{0} r_{0}}{A \beta^{2} \gamma^{3} \alpha(\eta) \epsilon}
$$

where $r_{0}=1.535 \times 10^{-18} \mathrm{~m}$ is the classical proton radius. 


\section{References}

[1] A.F. Haffmans, D. Maletić and A.C. Ruggiero, Particle Motion in ('rystalline Beams; Internal Report, BNL-604:36, April 1994.

[2] A.A. Garren et al., A User's Guide to SYNCH, FN-240, Fermilab, June 1985.

[3] E.D. Courant and H.S. Snyder, Theory of the Alternating (iradient Synchrotron, Ann. Phys. 3,1-48 (1958).

[4] J.D. Jackson, Classical Electrodynamics, New York, 1962. 

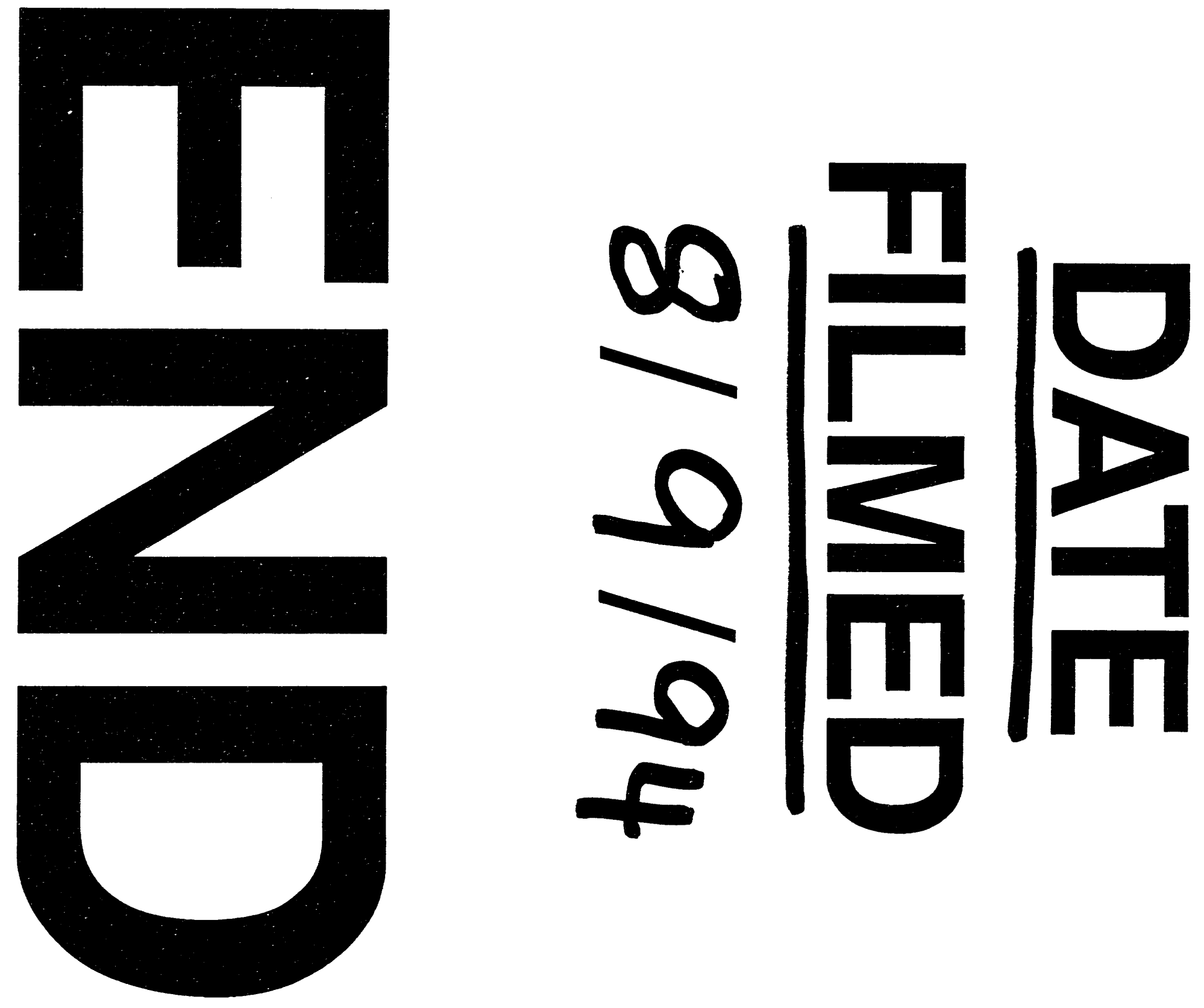
